Canadian

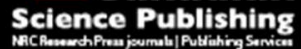

Canadian Journal of Physiology and Pharmacology Revue canadienne de physiologie et pharmacologie

\title{
Excessive Consumption of Fructose Causes Cardiometabolic Dysfunctions Through Oxidative Stress and Inflammation
}

\begin{tabular}{|r|l|}
\hline Journal: & Canadian Journal of Physiology and Pharmacology \\
\hline Manuscript ID & cjpp-2016-0663.R1 \\
\hline Manuscript Type: & Review \\
\hline Date Submitted by the Author: & 22-Dec-2016 \\
\hline Complete List of Authors: & $\begin{array}{l}\text { Bernardes, Nathalia; Universidade Nove de Julho } \\
\text { Ayyappan, Prathapan; University of Manitoba College of Medicine, } \\
\text { Physiology and Pathophysiology } \\
\text { Angelis, Katia; Universidade Nove De Julho } \\
\text { Bagchi, Ashim; University of Colorado at Denver - Anschutz Medical } \\
\text { Campus } \\
\text { Akolkar, Gauri; University of Manitoba, Institute of Cardiovascular Sciences } \\
\text { Dias, Danielle; Universidade Nove de Julho } \\
\text { Bello-Klein, Adriane; UFRGS, Physiology; } \\
\text { Singal, Pawan; Institute of Cardiovascular Sciences, }\end{array}$ \\
\hline Keyword: & $\begin{array}{l}\text { Metabolic Syndrome, Hypertension, Physical Activity, Inflammation, } \\
\text { Oxidative Stress }\end{array}$ \\
\hline \multicolumn{2}{|c}{} \\
\hline
\end{tabular}




\section{CJPP-2016-0663.R1}

\section{Excessive consumption of fructose causes cardiometabolic dysfunctions through oxidative stress and inflammation}

Nathalia Bernardes ${ }^{1}$, Prathapan Ayyappan, Katia De Angelis ${ }^{1}$, Ashim Bagchi, Gauri Akolkar, Danielle da Silva Dias ${ }^{1}$, Adriane Belló-Klein ${ }^{2}$ and Pawan K. Singal

Institute of Cardiovascular Sciences, St. Boniface Hospital Albrechtsen Research Centre, Department of Physiology and Pathophysiology, Rady Faculty of Health

Sciences, University of Manitoba, Winnipeg, Canada. ${ }^{1}$ Universidade Nove de Julho, Diretoria de Mestrado, Av. Francisco Matatazzo, 612, 10 andar, Centro de Pos Graduacao Stricto Sensu, Barra Funda, Sao Paulo, Brazil. ${ }^{2}$ Laboratory of Cardiovascular Physiology, Institute of Basic Health Science (ICBS), Universidade Federal do Rio Grande do Sul (UFRGS), Porto Alegre, Rio Grande do Sul, Brazil.

Short title: Fructose-induced cardiometabolic dysfunctions

\section{Address for Correspondence:}

Dr. Pawan K. Singal

Institute of Cardiovascular Sciences

St. Boniface Hospital Albrechtsen Research Centre

351 Tache Avenue

Winnipeg, Canada R2H $2 \mathrm{~A} 6$

Tel: (204) 235-3887

Fax: (204) 233-6723

Email: psingal@sbrc.ca 


\section{Abbreviations}

TNF- $\alpha$ : tumor necrosis factor- $\alpha$

8-iso-PGF2 $\alpha$ : 8 -isoprostaglandin F2 $\alpha$

AGEs: advanced glycation end

products

Ang II: angiotensin II

GPx: glutathione peroxidase

GSH: reduced glutathione

$\mathbf{H}_{2} \mathrm{O}_{2}$ : hydrogen peroxide

HDL: high-density lipoprotein

IKK $\beta$ : kappa B kinase beta

IL-10: interleukin-10

IL-18: interleukin-18

IL-1ß: interleukin-1 $\beta$

IL-6: interleukin-6

IR: insulin receptor

IRS-1: insulin receptor substrate 1

LDL: low-density lipoprotein

MCP-1: monocyte chemoattractant

peptide-1

NF- $\kappa$ B: factor nuclear $\kappa \mathrm{B}$ :

NLRP3: nucleotide-binding domain

(NOD)-like receptor protein 3

NO: nitric oxide

NOX: NADPH oxidase

$\mathbf{O}_{2}^{\bullet-}$ : superoxide anion radical

ONOO: peroxynitrite

POX-1: paraoxonase-1

RAS: renin-angiotensin system

RNS: reactive nitrogen species

ROS: reactive oxygen species

SNS: sympathetic nervous system

VLDL: very low density lipoprotein

XO: xanthine oxidase 


\begin{abstract}
A rapid rise in obesity as well as physical inactivity in industrialized countries is associated with fructose consumption-mediated metabolic syndrome having a strong association with cardiovascular disease. Although insulin resistance is thought to be at the core, visceral obesity, hypertension and hypertriglyceridemia are also considered important components of this metabolic disorder. In addition, various other abnormalities such as inflammation, oxidative stress and elevated levels of uric acid are also part of this syndrome. Life style changes through improved physical activity as well as nutrition are important approaches to minimize the metabolic syndrome and its deleterious effects.
\end{abstract}

Key words: Metabolic Syndrome, Hypertension, Physical Activity, Inflammation, Oxidative Stress. 


\section{Introduction}

Changes in diet have been studied extensively as a contributing factor to the development of obesity and associated metabolic diseases. Studies in the last decades have shown that increased obesity worldwide has paralleled increase of fructose consumption (Basciano et al. 2005; Elliott et al. 2002; Lustig et al. 2012). Epidemiological evidence shows that excessive sugar consumption adversely affects human health (WHO 2003), and this in turn induces most of the diseases associated with metabolic syndrome (Lustig et al. 2012; Tappy et al. 2010). Fructose is one of the main sugars found in corn syrup and has been used by the food industry to sweeten and produce flavor in food products. It is used in soft drinks, baked goods, candies, jams, preservatives, yogurts and sweetened as well as packaged products (Bray et al. 2004; Nakagawa et al. 2005). It constitutes almost $50 \%$ of the sugar that is a less expensive alternative.

For a clinical definition of metabolic syndrome, at least 9 different organizations as well as expert groups have proposed 7 different sets of diagnostic criteria (Kassi et al. 2011; Reaven 2011). Ultimately, definition for metabolic syndrome was created by a joint committee including the National Cholesterol Education Program's Adult Treatment Panel III (NCEP-ATP III) and the International Diabetes Federation (IDF). Accordingly, a person with metabolic syndrome must have a central obesity, high triglyceride level, low HDL-Cholesterol, hypertension and elevated fasting plasma glucose (Alberti et al. 2009). The insulin resistance and central obesity are considered significant factors among the causes of metabolic syndrome (Carr et al. 2004; Hu et al. 2004). Cluster of these factors in metabolic syndrome is directly related to increased cardiovascular risk and has reached epidemic levels worldwide (Basciano et al. 2005; 
Beltrán-Sánchez et al. 2013). Furthermore, the estimated prevalence of metabolic syndrome around the world ranges between 14 and 30\% (Table 1).

Consumption of high quantities of fructose by humans and animals leads to insulin resistance, lipid abnormalities, obesity, hypertension and renal dysfunction (Araujo et al. 2016; Basciano et al. 2005; Elliott et al. 2002; Farah et al. 2006; Hwang et al. 1987; Laville et al. 2009; Sanches et al. 2012; Tappy et al. 2010;). A recent metaanalysis concluded that a fructose intake $>50 \mathrm{~g} /$ day is associated with altered plasma triglycerides concentrations (Livesey and Taylor 2008). Large quantities of fructose in the circulation lead to rapid stimulation of lipogenesis and hypertriglyceridemia in the liver (Murakami et al. 1997). This reduces insulin sensitivity and leads to hepatic insulin resistance and dyslipidemia (Basciano et al. 2005; Elliott et al. 2002). Hepatic metabolism of fructose favors lipogenesis and reduces insulin secretion as well as leptin production. Production of leptin is also influenced by insulin as a result decline in insulin concentration leads to lower leptin concentration (Sato et al. 1996). Since insulin and leptin are important regulators of food intake and body weight, the impairment of secretion and production of these hormones by fructose may contribute to increased weight gain (Bray et al. 2004).

An excessive consumption of sugar, regardless of weight gain, increases the risk for metabolic syndrome and cardiovascular disease via development of insulin resistance, hypertension and inflammation (Malik et al. 2010). Visceral obesity, insulin resistance and hypertension trigger increase in oxidative stress, where latter is considered to be a pathogenic link between obesity and insulin resistance along with endothelial dysfunction. In addition to increased oxidative stress, excess weight gain and obesity are also associated with the elevated systemic inflammation, disturbances in the renin angiotensin system and enhanced lipid as well as protein oxidation (Van Gaal 
et al. 2006) contributing in the development of several cardiovascular diseases (Hulsmans et al. 2012).

The toxicity caused by the consumption of excess fructose has been considered similar to the consumption of alcohol (Lustig et al. 2012). This includes: hypertension; increase in uric acid; high triglycerides; insulin resistance; increased synthesis of fat in the liver; increased liver glucose production combined with insulin resistance; and damage to biological macromolecules, such as lipids, proteins and DNA.

Subjects with metabolic syndrome also have autonomic nervous system dysfunction and/or activation of the sympathetic nervous system. An activation of the sympathetic nervous system in the metabolic syndrome is reflected as increased blood pressure and heart rate, decreased heart rate variability, baroreceptor dysfunction, enhanced lipolysis in visceral fat, increased muscle sympathetic nerve activity and high urine or plasma catecholamine concentrations. Thus, a rise in sympathetic activity in individuals with metabolic syndrome has bad prognosis which creates a high-risk population (Tentolouris et al. 2008).

Recently, it was reported that a fructose overload promotes impairment in cardiac autonomic modulation associated with inflammation and oxidative stress in hypertensive ovariectomized rats (Conti et al. 2014). In addition, these rats showed increased weight of the adipose tissue which is known to release a large number of cytokines and bioactive mediators. The latter negatively influences glucose and lipid homeostasis, blood pressure, coagulation, fibrinolysis and inflammation, which may lead to endothelial dysfunction and atherosclerosis (Grattagliano et al. 2008; Lau et al. 2005; Van Gaal et al. 2006).

Apparently, epidemiological as well as biochemical studies suggest that the high dietary intake of fructose is an important causative factor in the development of the 
metabolic syndrome. This review focuses on high consumption of fructose as a critical factor contributing to the development of metabolic and cardiovascular complications in relation with hypertension, uric acid, oxidative stress and inflammation. The review also highlights the beneficial role of physical activity and nutrition on various components of the metabolic syndromes.

\section{Fructose and Hypertension}

High blood pressure is considered as one of the main components of metabolic syndrome in about $30-40 \%$ of the hypertensives (Abdilla et al. 2007). Since hypertension is a comorbidity associated with obesity, insulin resistance, hyperinsulinemia, and hyperlipidemia, it is very important to determine the effects of fructose consumption on blood pressure (Elliot et al. 2002). High fructose intake was associated with higher blood pressure among adults in the United States without a history of hypertension (Jalal et al. 2010). In fact, fructose has also been shown to increase blood pressure when administered acutely or when consumed in beverages (Brown et al. 2008). Cohort studies have found a positive association between sugarsweetened beverages consumption and incidence of hypertension (Dhingra et al. 2007; Nettleton et al. 2009).

Studies on rodent models demonstrated that a high-fructose diet leads to hypertension through multiple factors such as: uric acid production (Reiser, 1985), hyperinsulinemia (Daly et al. 1997), aldehyde formation (Vasdev et al. 1998), altered vascular reactivity (Feig et al. 2008; Verma et al. 1996;), inhibition of endothelial nitric oxide synthase system (Glushakova et al. 2008, Zhao et al. 2009); stimulation of the sympathetic nervous system (Brito et al. 2008), and by directly increasing sodium absorption in the gut (Singh et al. 2008). Fructose mediated reduction of endothelial NO levels is recognized as a known mechanism for inducing insulin resistance (Roy et al. 
1998). It is also reported that endothelial NOS deficient mice exhibit the features of metabolic syndrome (Cook et al. 2003). The consumption of fructose for 8 weeks in rats induced metabolic syndrome associated with renal disturbances characterized by renal hypertrophy, arteriolopathy, glomerular hypertension and cortical vasoconstriction (Sánchez-Lozada et al. 2007). There are some studies which did not find an association between fructose intake and elevated blood pressure levels (Bezerra et al. 2001; D'Angelo et al 2005; Forman et al. 2009). This may probably be due to the differences in the amount of fructose ingested

The increased expression of angiotensin II type 1 (AT1) receptor in adipose tissue, as well as hypertension were found in rats with fructose feeding, suggesting that AT1 receptors might play an important role in the pathophysiology of metabolic and hemodynamic abnormalities induced by fructose (Giacchetti et al. 2000). The dysfunction caused by fructose overload seems to be associated with the autonomic nervous system dysfunction, which is characterized by sympathetic hyperactivity, particularly in the cardiovascular and renal systems. Studies show that sympathetic activation is involved in the pathogenesis of the various components of metabolic syndrome such as hypertension, obesity, and insulin resistance (Rocchini et al. 2010; Tentolouris et al. 2008; Tentolouris et al. 2006; Vaz et al. 1997).

In fact, there is consistent evidence for the role of sympathetic nervous system as well as RAS in fructose induced cardiovascular and renal changes (Brito et al. 2008; Farah et al. 2006; Kamide et al. 2002; Senador et al. 2010; Verma et al. 1999). One of the consequences of renal damage is the development of arterial hypertension. Thus, nutrition is an important variable which may alter the risk for renal disease and hypertension-induced kidney damage (Farah et al. 2006; Haffner et al. 1992). 
An autonomic modulation may be an initiating mechanism for the cluster of symptoms associated with cardiometabolic disease in fructose-fed mice (De Angelis et al. 2012). It is to be noted that the nervous system reflexively regulates the inflammatory response, just as it controls heart rate and other vital functions (Tracey 2002). An increase in sympathetic activity is a mechanism for blood pressure elevation conferring cardiovascular risk (Esler 2000). Thus, the metabolic changes associated with fructose-induced hypertension may be secondary to an increase in sympathetic activity (Hwang et al. 1987). In addition, rats with fructose overload for 10 weeks had insulin resistance, obesity, hypertension, autonomic dysfunction, decreased baroreflex sensitivity, decreased heart rate variability, increased sympathovagal balance, increased renal sympathetic nerve activity (Moraes-Silva et al. 2013) and diastolic dysfunction (Mostarda et al. 2012). Moreover, fructose overload for 18 weeks in female rats induced elevated arterial pressure and the cardiac sympathetic response associated with insulin resistance (Silva et al. 2011).

Activation of sympathetic nervous system during metabolic syndrome worsens the prognosis of this high-risk population. Although central obesity and insulin resistance are associated with increased sympathetic nervous system activity, the mechanisms linking metabolic syndrome and sympathetic nervous system activation are complex (Tentolouris et al. 2008). Collectively, fructose induced hyper activity of sympathetic nervous system leads to the activation of RAS along with increased release of catecholamines resulting in vasoconstriction and hypertension. In addition, fructose mediated hyperuricemic condition and insulin resistance can also lead to endothelial dysfunction that further contributes to the development of hypertension. 


\section{Fructose and Uric acid}

One of the established links between increased prevalence of the metabolic syndrome and fructose consumption is elevated serum uric acid concentration (Figure 1). Fructose has the ability to raise uric acid, which inhibits endothelial function (Nakagawa et al. 2006). During metabolism, phosphorylation of fructose into fructose1-phosphate is catalyzed by the enzyme fructokinase, using ATP as a phosphate donor. Due to the lack of negative feedback mechanism for the inhibition of fructokinase, accumulation of phosphorylated substrate along with depletion of intracellular phosphate and stimulation of AMP deaminase leads to degradation of nucleotides to uric acid (Hallfrisch 1990).

Sugar consumption has been correlated with uric acid concentrations in American adults (Gao et al. 2007). An association among sugar sweetened beverages, serum uric acid levels, and blood pressure was reported in a cross sectional analysis of 4867 adolescents (Nguyen et al. 2009). Many studies have established association of increased concentration of uric acid in serum with the development of hypertension (Jossa et al. 1994). A randomized trial among men in Spain also showed that pharmacological lowering of uric acid levels prevented high fructose consumption mediated increase in blood pressure (Perez-Pozo et al. 2010). In experimental hyperuricemia, RAS is reported to mediate adverse endothelial and vascular effects (Mazzali et al. 2001). This strongly suggests the involvement of uric acid in inducing hypertension and renal disease via angiotensin II and NO.

Endothelial dysfunction is regarded as a hallmark of metabolic syndrome (Deedwania 2003). Elevated levels of uric acid lead to insulin resistance, further resulting in impaired endothelial function. In addition, uric acid potentially reduces endothelial NO bioavailability both in cell culture and experimental animal models, 
leading to vasoconstriction and over production of ROS (Khosla et al. 2005). Uric acid mediated endothelial dysfunction is associated with mitochondrial dysfunction and decreased intracellular ATP production that further amplifies the development and progression of hypertension and other vascular diseases (Sanchez-Lozada et al. 2012). Due to its pro-oxidant nature, uric acid accelerates lipid peroxidation and inflammation resulting in the impairment of normal reverse cholesterol transport (Srikanthan et al. 2016). Moreover, uric acid has the ability to stimulate monocytes to produce tumor necrosis factor- $\alpha$ (TNF- $\alpha)$ and thus induces a pro-inflammatory condition exacerbating tissue damage (Srikanthan et al. 2016). Uric acid is reported to stimulate lipogenesis and inhibit AMP kinase thereby prevents the oxidation of fatty acids and ATP generation. In addition, uric acid induces mitochondrial oxidative damage accompanied by reduction in aconitase activity and citrate accumulation leading to increased fat synthesis and further accelerates the development of metabolic syndrome (Johnson et al. 2013). Recently, a 10 year long longitudinal study showed that high level of serum uric acid is the best predictor for hypertension and other metabolic diseases (Sun et al. 2015). All these data together suggests that there is a strong relation between fructoseinduced hyperuricemia and the development of metabolic syndrome. Thus, targeting hyperuricemia in fructose-mediated metabolic syndrome may offer new therapeutic strategies to manage the disease progression.

\section{Fructose and Oxidative Stress}

Oxidative stress is a well-recognized phenomenon playing an important role in the pathogenesis of endothelial dysfunction, hypertension, inflammation, and atherosclerotic cardiovascular disease (Figure 1). It is defined as an impaired balance between free radical production and endogenous antioxidant capacity, resulting in the accumulation of oxidative products (Sies et al. 1997; Singal et al. 1998). Reactive 
oxygen and nitrogen species initiate cascades of events including DNA damage, protein nitration/oxidation, lipid peroxidation, and activation of matrix metalloproteinases contributing to the dysfunction of various organ systems (Khaper et al. 2010; Paravicini and Touyz 2006; Shen 2010; Vasdev et al. 2006).

On the other hand, cells have evolved various enzymatic defenses such as superoxide dismutase, catalase and glutathione peroxidase (GPx), and nonenzymatic antioxidants like reduced glutathione and many other antioxidant vitamins to detoxify free radicals (Bryan et al. 2013; Singal et al. 1998). Various experimental and clinical observations indicate that oxidative stress is an important pathogenic mechanism in metabolic syndrome and its complications (Furukawa et al. 2004; Grattagliano et al. 1998). Metabolic syndrome changes the mitochondrial metabolism, lipid storage and increases the levels of circulating free fatty acid, all these favoring the imbalance between increased free radical production and reduced antioxidant defense. Thus oxidative stress is strongly linked with the onset and progression of metabolic syndrome like hypertension, insulin resistance, endothelial dysfunction and other vascular complications in this condition (Grattagliano et al. 2008).

Numerous studies have revealed that high levels of fructose consumption promote oxidative stress via the imbalance between the production of free radicals and reduced endogenous antioxidant status which leads to cardiovascular abnormalities and complications (Jaiswal et al. 2015; Kaneto et al. 1996). Fructose is reported to accelerate the production of cardiac and vascular superoxide anions (Delbosc et al. 2005; Shinozaki et al. 2000). Increased generation of cardiac superoxide anions is found to be due to fructose-mediated overexpression of p22 phox, an active subunit of NADPH oxidase. The latter catalyzes the transfer of a single electron to molecular oxygen to produce superoxide and other free radicals in different tissues (Chabrashvili 
et al. 2002; Taniyama and Griendling, 2003; Vaziri 2004). This increased activity of NADPH oxidase contributes to the pathogenesis of oxidative stress and NO inactivation in fructose-fed rats (Roberts et al. 2000).

Similarly, rats fed with a diet rich in refined sugars and fats exhibited oxidative stress, reduced NO bioavailability and inhibited NOS and Akt (a protein kinase NO synthase activator) (Roberts et al. 2006a). Fructose induced metabolic syndrome is characterized by increased uric acid, which stimulates NADPH oxidase activity and increases ROS production and inflammatory mediators in adipocytes, heart and other vascular tissues. Thus, fructose reduces NO bioavailability and raises protein nitrosylation and lipid peroxidation (Delbosc et al. 2005; Sautin 2007). Recently, it was found that fructose can also induce mitochondrial dysfunction and apoptosis via oxidative stress and, thus, leads to insulin resistance and the development of metabolic syndrome (Jaiswal et al. 2015). Moreover, fructose-induced oxidative stress is also linked to the development of cardiac hypertrophy and hypertension (Delbosc et al. 2005).

Fructose consumption through the production of uric acid, can activate prooxidant enzymes such as xanthine oxidase which can initiate as well as promote the production of ROS (Kang et al. 2016). Changes in NO metabolism involving its derivatives, peroxynitrite and nitrosothiols, may have important implications in the appearance of metabolic syndrome associated with endothelial dysfunction (Myers et al. 1990). Peroxynitrite is a highly reactive and cytotoxic radical that attacks and denatures lipids, nucleic acids, and proteins (Halliwell 1997). Peroxynitrite reacts with tyrosine residues producing nitrotyrosine, which is used as a marker of ROS-NO interaction (Eiserich et al. 1998a, $b$; Halliwell 1997). Rats fed with fructose diet for 2 months show 
a significant accumulation of nitrotyrosine in kidney and heart tissue denoting, increased NO inactivation by ROS (Roberts et al. 2000).

Oxidative stress itself can promote endothelial dysfunction via limiting the bioavailability of NO through ROS-mediated inactivation of preformed NO (Eiserich et al. 1998a,b; Halliwell 1997). Oxidative stress reduces NO production and promotes superoxide generation by NOS uncoupling (Landmesser et al. 2003). Thus, oxidative stress adversely affects cardiovascular function and structure by promoting inflammation via $\mathrm{NF} \kappa \mathrm{B}$ activation, endothelial injury and vascular smooth muscle cell proliferation (Rodriguez-Itrube et al. 2004).

Fructose is considered as a highly lipogenic sugar that leads to increased production of triglycerides. Another mechanism capable to induce oxidative stress in fructose overload is through hypertriglyceridemia. The latter leads to increased lipid peroxidation and increases the secretion of VLDL and LDL cholesterol (Basciano et al. 2005; Moore et al. 2014). High levels of LDL cholesterol under oxidative stress lead to the formation of oxidized-LDL which can mediate inflammatory response with cardiac structural and functional abnormalities (Dokken et al. 2008; Kang et al. 2016). In another study of obesity model, high fructose diet caused a significant increase in lipogenesis that further accelerated ectopic lipid deposition and mitochondrial mediated oxidative stress along with declined antioxidant defense (Crescenzo et al. 2013). Oxidative stress of visceral fat is also considered as an early marker of metabolic syndrome in animals and humans. Moreover, it is suggested that the oxidative stress in the adipose tissue could be considered as a new therapeutic target for the metabolic syndrome (Hopps et al. 2010). Systemic oxidative stress plays an important role in the deposition of visceral fat and a positive correlation is found between the distribution of visceral fat and metabolic syndrome (Fujita et al. 2006). Consumption of high fructose 
diet induces hyperglycemia and impairs glucose tolerance which is accompanied by hyperinsulinemia and insulin resistance (Bigonia et al. 2012; Hozayen et al. 2016). Auto-oxidation of glucose or fructose is one of the important consequences of hyperglycemia resulting in the formation of advanced glycation end products (AGEs) (Guglielmotto et al. 2012). Production of AGEs by fructose is ten times greater than those produced by produced by glucose (Miller and Adeli 2008). Increased level of AGEs promotes the production of ROS via NADPH oxidase and mediates inflammatory pathways and thereby leads to the pathophysiology of various cardiometabolic dysfunctions (Cheng et al. 2014; Farahmand et al. 2003; Miller and Adeli 2008).

Various studies have revealed that subjects with metabolic syndrome had decreased antioxidant protection, reduced total antioxidant capacity, increased lipid peroxidation, increased DNA damage, and elevated total plasma lipid peroxides (Demirbag et al. 2006; Palmieri et al. 2006). In another study, presence of hypertension was observed in $80 \%$ subjects under study with metabolic syndrome and there was a negative correlation between total antioxidant status levels and blood pressure (Demircan et al. 2008). A decline in antioxidant enzyme activities was found in subjects with metabolic syndrome (Abdilla et al. 2007). Altogether these evidences suggest that insulin resistance, oxidative stress and mitochondrial dysfunction are interrelated in fructose-induced metabolic syndrome and the alteration in any of these parameters leads to severe complications associated with metabolic syndrome (Figure 1).

\section{Fructose and Inflammation}

Inflammation is a pathological process central to the development of cardiovascular diseases and metabolic syndrome. Inflammation is mediated by a variety of cell types including macrophages, lymphocytes, endothelial cells and vascular smooth muscle cells (Figure 2). Different cells that participate in vascular inflammation 
produce common cytokines and specific membrane receptors, permitting to them communicate by expression and recognition of multiple pro-inflammatory and antiinflammatory cytokines (Renna et al. 2013).

The ligands involved in inciting the inflammatory response include: prostaglandins, C-reactive protein, soluble CD40 ligand, adiponectin, inflammatory cytokines such as TNF- $\alpha$, IL-6 and many others. Many of these are increasingly used as biomarkers for the systemic inflammation associated with metabolic syndrome (Donath and Shoelson 2011; Rabkin 2009). Cytokines can drive multiple cellular processes including mitogenesis, development, gene expression, fibrosis, and chemotaxis (Tedgui and Mallat 2006). Proinflammatory cytokines often lead to the activation of NF- $\kappa \mathrm{B}$ which acts as a key molecule for the transcription of numerous genes; the expression of some may be maladaptive (Dhingra et al. 2009; Hansson and Libby 2006; Paukku and Silvennoinen 2004).

The endothelium has the properties to promote vasodilatation by releasing NO, prostacyclin and other molecules. In various chronic diseases, endothelium becomes dysfunctional and promotes inflammation. Indeed, the inflammatory process is modulated by the activity of several families of enzymes, including cyclooxygenases, lipoxygenases, NADPH-dependent oxidases, NOS and peroxidases (Grattagliano et al. 2008; Libby et al. 2002; Ross 1999; Verma and Anderson 2002). Inflammation, one of the important components of metabolic syndrome, increases the production of ROS, resulting in increased oxidative stress (Demircan et al. 2008). Therefore, chronic inflammation and an abnormal pro-oxidant state are found in metabolic syndrome and may play a key role in its pathogenesis (Festa et al. 2000; Ridker et al. 2003).

High fructose diet-induced metabolic syndrome is associated with inflammatory changes in many tissues due to increased monocyte-macrophage infiltration 
(Glushakova et al. 2008). Fructose-induced hyperlipidemia leads to lipid retention within the hepatocytes which triggers the generation of ROS at different intracellular levels and activation of NF- $\kappa \beta$ and cytokine release (Arkan et al. 2005; Dalen et al. 2006; Tilg and Hotamisligil 2006; Tsochatzis et al. 2006). This is because inflammation enhances hepatic lipid peroxidation, leading to changes in physiochemical properties of membranes (Grattagliano et al. 2000; Videla et al. 2004), as well as fibroblasts activation (Casini et al. 1997). The excessive fat accumulation in metabolic syndrome induces free radical generation and favors oxidative damage in adipose tissue (Furukawa et al. 2004). Visceral obesity represents a low-grade systemic inflammation, as reflected by elevated serum markers, such as C-reactive protein and TNF- $\alpha$ (Diehl 2004).

Recent evidence also supports the fact that fructose consumption may promote accumulation of visceral adiposity or ectopic fat deposition (Stanhope et al. 2009), one of the key features of a dysmetabolic state, leading to the risk of cardiovascular disease (Despres et al. 2008). It has been described that pathological adipokine expression during metabolic syndrome is associated with the expansion of visceral adiposity in central obesity and leads to dysregulated modulation of insulin sensitivity, lipid profile, endothelial dysfunction and inflammatory state (Brietzke 2010).

Insulin resistance can occur via the activation of proinflammatory cytokine expression and oxidative stress (Figure 2). ROS can activate NF- $\kappa \mathrm{B}$ and trigger proinflammatory monocyte chemoattractant peptide- 1 expression, inducing the production of cytokines, TNF- $\alpha$ and IL-6, thereby increasing macrophage infiltration and adipocyte death (Furukawa et al. 2004; Minamino et al. 2009; Ouchi et al. 2011; Styskal et al. 2012; Weisberg et al. 2003). Release of TNF- $\alpha$ and IL-6 by ROS also decreases insulin sensitivity via inhibiting the IRS-1 protein (Hotamisligil 1999; Styskal et al. 2012). One 
of the mechanisms by which fructose induces cardiac inflammation and fibrosis is found to be mediated via CD36 activated nucleotide-binding domain (NOD)-like receptor protein 3 (NLRP3) inflammasome (Kang et al. 2016).

Inflammatory mechanism activates stress kinases and results in serine phosphorylation of IR and IRS-1 that inhibits the tyrosine phosphorylation of IR and IRS-1 and diminishes insulin signaling and action which causes insulin resistance (Boucher et al. 2014; Henriksen et al. 2011; Styskal et al. 2012). Inhibition of these stress activated kinases is reported to be associated with improved insulin sensitivity (Henriksen et al. 2011; Yuan et al. 2010). Indeed, ROS and endoplasmic reticulum stress can induce kappa B kinase beta to activate $\mathrm{NF} \kappa \mathrm{B}$, thereby stimulating the expression of many downstream pro-inflammatory cytokine gene targets (Arkan et al. 2005; Donath and Shoelson 2011).

Evidence suggests that insulin resistance is regulated by cytokines and other mediators released from mesenteric adipocytes (Tilg and Hotamisligil 2006). Adipokines appear to play a central role and may act as a cellular link in mediating metabolic syndrome, insulin resistance and endothelial dysfunction. Many of the proinflammatory adipokines like IL-6, leptin, TNF- $\alpha$, angiopoietin-like protein 2 , CCchemokine ligand 2, CXC-chemokine ligand 5, IL-18, lipocalin 2, nicotinamide phosphoribosyl transferase, resistin, and retinol-binding protein 4 exert multiple actions in a variety of cellular processes leading to a complex array of abnormalities characteristic of metabolic syndrome (Lau et al. 2005; Ouchi et al. 2011). Among different adipokines, adiponectin is the most significant anti-inflammatory adipokine. ROS, TNF- $\alpha$ and IL-6 are known to inhibit adiponectin (Hosogai et al. 2007). The levels of C-reactive protein, TNF, IL-6, IL- 18 and oxidized LDL are increased in obese subjects with metabolic syndrome (Girona et al. 2007; Van Guilder et al. 2006). 
Individuals with metabolic dysfunction have macrophage accumulation in adipose tissue that further worsens the inflammatory process (Apovian et al. 2008). Proinflammatory condition can induce and be exacerbated by a pro-oxidant environment, which is strongly associated with obesity in both humans and laboratory animals (Styskal et al. 2012).

Increased accumulation of macrophages is also known to contribute to redoxinflammatory status in obesity. Obese mice express M1 macrophages in adipose tissue that produce pro-inflammatory cytokines including TNF- $\alpha$ and IL- 6 as well as ROS and RNS. Moreover, lean mice express the M2 phenotype macrophages, which stimulate production of the anti-inflammatory cytokine IL-10 and suppress the expression of proinflammatory cytokines (Ouchi et al. 2011).

High homocysteine and low nitrosothiol levels may be involved in inflammation in subjects with metabolic syndrome (Grattagliano et al. 2008). Homocysteine acts as an N-methyl-D-aspartate agonist, thus decreasing the availability of NO and impairing arterial vasodilation capacity (Lipton et al. 1993) and circulating nitrosothiols act as free NO donors for vascular tone modulation (Myers et al. 1990). In an experimental model of metabolic syndrome, rats fed with fructose for 12 weeks showed hypertension, dyslipidemia, insulin resistance, cardiovascular remodeling, inflammation as demonstrated by increased C-reactive protein, vascular inflammation, increased $\mathrm{NF} \kappa \mathrm{B}$ expression, vascular cell adhesion protein 1, and proatherogenic cytokines, suggesting the involvement of RAS in the mediation of inflammation and vascular injury (Renna et al. 2013). Evidence from human and animal models also suggests that a blockage of over-activation of RAS improves insulin sensitivity (Lastra et al. 2009).

The central nervous system plays an important role in the inflammatory response and vagus nerve dysfunction is related to the progression of inflammation, owing to the 
impairment of the cholinergic anti-inflammatory pathway (Tracey 2002). The sympathetic over activity also induces inflammation (Chrousos 1995; Mohamed-Ali et al. 2000) mainly by increasing IL-6 production. Thus, the increased levels of inflammatory markers seen in the metabolic syndrome may be mitigated, at least in part, by inhibiting/reducing sympathetic nervous system overactivity (Tentolouris et al. 2006). Recently, Castro et al. (2015) put forward a pathogenic sequence of metabolic, endocrine and inflammatory changes induced by fructose. Fructose-induced hypertriglyceridemia along with elevated activity of glucokinase leads to lipid peroxidation with a decline of GSH content. The resultant oxidative stress further favors the release of pro-inflammatory cytokines and inflammation mediated tissue damage.

The inflammatory and oxidative processes in obesity, lead to increased adipose dysfunction and may involves micro-RNAs (Hulsmans et al. 2011). Elevated melanogenesis in adipose tissue may indicate an anti-inflammatory and antioxidant role for melanin (Page et al. 2011). Inflammation and oxidative stress are the major features of the metabolic and cardiovascular abnormalities and are fundamentally inseparable from the pathological processes of metabolic syndrome (Figure 2). Through common regulatory controls and synergistic cellular mechanisms, cross-promotion of oxidative stress and inflammation occurs in a classic vicious cycle that spans through the disease initiation and progression, and may represent a common link between metabolic syndrome and cardiovascular disease (Bryan et al. 2013; Khaper et al. 2010).

\section{Lifestyle Approaches to Address Fructose based Cardiometabolic Dysfunctions}

Unhealthy diet and physical inactivity are the major risk factors for chronic diseases. Several studies have demonstrated that the pathogenesis of metabolic syndrome is largely attributable to dietary factors and physical activity levels. Thus, physical activity and nutrition are important approaches to minimize the deleterious 
effects of metabolic syndrome. In fact, evidence of cardiovascular, metabolic and autonomic benefits of chronic exercise training has led many researchers to suggest regular physical training as an important non-pharmacological intervention in both prevention and management of hypertension (Moraes-Silva et al. 2010; Wichi et al. 2009), diabetes (De Angelis et al. 2006; Mostarda et al. 2014; Quinteiro et al. 2015), insulin resistance (Chien et al. 2012; De Angelis et al. 2009; Schaan et al. 2010), obesity (Paulino et al. 2010) and metabolic syndrome (Castro et al. 2015; Machi et al. 2013; Moraes-Silva et al. 2013; Morvan et al. 2013; Sanches et al. 2012).

\section{Physical Activity}

Beyond the well-documented beneficial effects of exercise and body weight reduction in the prevention of insulin resistance; physical activity ameliorates various diseases associated with metabolic syndrome (Dixon et al. 2004; Ivy 1997). Overall, fitness level is a significant predictor of metabolic syndrome (Katzmarzyk et al. 2004), and this may be mediated, in part, by the effects of exercise on oxidative stress. Studies showed that resistance training exercise decreases oxidative stress in overweight older subjects (Parise et al. 2005; Vincent et al. 2006).

Poor cardio-fitness and respiratory physical inactivity are inversely proportional to the incidence of chronic metabolic diseases and premature mortality. Subjects with less $\mathrm{O}_{2}$ consumption had a significant inverse association with the risk of metabolic syndrome (Lakka et al. 2003). Men with elevated blood pressure and other metabolic syndrome risk factors showed a reduction in blood pressure as well as fasting 8-isoPGF2 $\alpha$ levels along with an increase in NO availability after three weeks of lifestyle modification, such as exercise and diet. The study showed that diet and exercise intervention mitigated the risks for cardiometabolic dysfunction and its progression (Roberts et al. 2002). 
Moreover, other studies from the same group also found a decrease in myeloperoxidase, lipid hydroperoxides and improved function of HDL along with antiinflammatory protection against LDL oxidation in obese men (Roberts et al. 2006b, c). Exercise and diet induced weight loss, decreased oxidative stress and insulin sensitivity in adults with metabolic syndrome. It was observed that a 4-7 month of exercise and calorie restriction reduced oxidized LDL and lipid hydroperoxides without altering the levels of HDL lipid hydroperoxides (Rector et al. 2007). Sanches et al. (2012) observed that aerobic exercise training on a treadmill (50-60\% of maximal running speed) for 8 weeks attenuated the increase in blood glucose and triglycerides concentrations, reduced insulin resistance and improved cardiovascular autonomic modulation in fructose-fed ovariectomized rats. However, the metabolic disorders in hypertensive rats, after ovarian hormone deprivation, blunt some of the exercise training benefits.

The low intensity exercise training (20-30\% of maximal running speed) for 8 weeks in the fructose-fed rats with metabolic syndrome improved insulin sensitivity, baroreflex sensitivity, myocardial capillarity, circumferential wall tension, as well as promoted a reduction in white adipose tissue, collagen fibers in the aorta and left ventricle (Morvan et al. 2013). Walking training on a treadmill for 8 weeks in male rats with fructose overload (100 g/l for 19 weeks), resulted in a slight decrease in blood pressure, decrease in triglycerides, adipose tissue deposits and insulin resistance as well as improved baroreflex sensitivity (Machi et al. 2013). The same training during 9 weeks seems to be better for preventing morphological dysfunctions in pancreas and metabolic disorders. However, exercise with moderate intensity $(50-60 \%$ of the maximum running speed) failed to show such benefits (Amaral et al. 2015).

In another study, exercise training on a treadmill $(50-70 \%$ of the maximum running speed) during 10 weeks in male rats with fructose overload (100 g/l) had a 
preventive role in the deleterious effects induced by fructose consumption. Exercise improved hemodynamics, autonomic and metabolic parameters (Moraes-Silva et al. 2013). Improved insulin sensitivity, decrease blood pressure and body weight were correlated with maintenance of diastolic function (Mostarda et al. 2012) and effectively prevented metabolic abnormalities, arterial and intraocular pressure associated with peripheral autonomic system improvement (Castro et al. 2015). A diet containing 20\% fructose and an endurance training for 12 weeks acted synergistically to increase glycogen content in liver and skeletal muscle in rats (Murakami et al. 1997). It is interesting to note that in animals that have been fed with high fructose diet, the ability of muscle to metabolize glucose was reduced, whereas its ability to oxidize fatty acids was increased.

Exercise training on a treadmill for 10 weeks ( $60 \%$ maximal oxygen uptake) and caloric restriction $(20 \mathrm{kcal} /$ day lower than that consumed by control rats) prevented cardiac dysfunction and reduced visceral fat mass, circulating leptin, epinephrine, and norepinephrine levels. Exercise training improved cardiac function which was associated with a better NO bioavailability and redox balance, evaluated by reduced to oxidized gluthathione ratio (GSH/GSSG) (Paulino et al. 2010). Moderate exercise on a treadmill for 26 weeks prevented hypothalamic inflammation against metabolic damage induced by a high-fructose diet in male mice (Yi et al. 2012). Furthermore, exercise training on a treadmill for 16 weeks attenuated the development of hepatic inflammation, fibrosis and macrophage infiltration caused by ingestion of high-fat diet and high-fructose diet (Kawanishi et al. 2012). Moreover, swimming training for 4 weeks reduced insulin resistance (Chien et al. 2012), partially improved ventricular function, increased serum adiponectin level and its cardiac expression (Sakr 2013) in rats fed with fructose. 
A meta-analysis of randomized and clinically controlled trials, on the effects of exercise training on cardiovascular risk factors, in patients with metabolic syndrome suggests that dynamic endurance training has a favorable effect on most of the cardiovascular risk factors associated with the metabolic syndrome (Pattyn et al. 2013). A cohort study, comprising 332 adults with metabolic syndrome undergone 14 weeks of an exercise training program (40-60\% target oxygen consumption reserve), showed attenuation of the adverse cardiometabolic response. Thus supporting the role of evidence based, individualized exercise programme to reduce the prevalence of adverse metabolic reprogramming in chronic diseases (Dalleck et al. 2015). A recent study also showed that exercise training immediately after fructose consumption increased the oxidation of fructose and reduced its storage in obese men (Egli et al. 2016).

\section{Nutritional Approaches}

Nutrients appear to play different roles in the management of metabolic diseases. In fact, consumption of refined sugar, especially fructose, has been suspected to be a key factor in the development of insulin resistance and metabolic syndrome (Sorensen et al. 2005). Several aspects of diet, including westernized diets characterized by highsaturated and trans fat intake, refined carbohydrate and high sugar consumption contribute to metabolic syndrome (Liu and Manson 2001; Liu and Willett 2002; Roberts and Barnard 2005). The WHO, the Food and Agriculture Organization and the American Heart Association recommended a restriction of free sugar intake in order to prevent diabetes and obesity, based on their potential detrimental effects on metabolism. The suggested intake of free sugars should not be any more than $10 \%$ of calories. But it is still in debate whether sufficient evidence exists to justify the restriction of sugar intake in terms of prevention of obesity and diabetes. 
A diet rich in sugar increases cholesterol, triglycerides and the risk for coronary diseases. In observational and epidemiological studies, a high saturated fat intake has been associated with a higher risk of impaired glucose tolerance, higher fasting glucose and insulin levels (Feskens et al. 1995; Parker et al. 1993; Te Morenga et al. 2014). Feeding sugars as compared to starch showed undesirable changes in metabolic risk factors such as blood triglycerides, total cholesterol and its lipoprotein distribution, insulin and uric acid. Other dietary components such as saturated fats can also magnify the adverse metabolic effects of the sugars (Reiser 1985).

On the other hand, consumption of olive oil - a rich source of phenolic antioxidant compounds, could provide lower plasma oxidized LDL and lipid peroxide levels and higher glutathione peroxidase activity, suggesting beneficial effects in metabolic syndrome. In fact, mediterranean diet which contains a high amount of olive oil, fish, vegetable and low consumption of alcohol provide a better antioxidant capacity (PitSavos et al. 2002; Trichopoulou et al. 2003; Velazquez-Lopez et al. 2014). Consumption of olive oil rich diet has also been associated with a reduced incidence of hypertension, suggesting that a diet regimen with well balanced carbohydrates and fats could be used to correct metabolic abnormalities in patients with metabolic syndrome (Fito et al. 2005).

Large number of studies showed that treatment with dietary antioxidants ameliorated fructose-induced oxidative stress and metabolic syndrome. Treatment with resveratrol was found to reduce fructose-induced metabolic alterations via its antioxidant mechanism and inhibition of NADPH oxidase (Cheng et al. 2014). Grape polyphenols were found to reduce fructose-induced oxidative stress and other metabolic alterations in type 2 diabetic patients (Hokayem et al. 2013). Fructose fed rats treated with garlic and onion showed significant protection against adverse effects 
induced by fructose. These vegetables were able to reverse the increased arterial pressure, insulin resistance, increased NADPH oxidase activity and lipid peroxidation and attenuated vascular inflammation (Vazquez-Prieto et al. 2011). Rats treated with $70 \%$ fructose for 45 days developed insulin resistance, increased blood pressure, sympathetic activation as well as parasympathetic inhibition (Bhatt et al. 2012) treatment with Enicostemma littorale blume in those rats demonstrated a preventive role against fructose-induced insulin resistance and associated cardiovascular complications, proposing that antioxidant phytomedicines could be used as a complementary and alternative medicine for the prevention and management of metabolic syndrome (Bhatt et al. 2012). Alpha-lipoic acid was found to be effective to disrupt the pathological changes induced by fructose by upregulating antioxidant status and down regulating inflammatory responses in rats (Castro et al. 2015). Recently, it was reported that treatment with the antioxidant compound cinnamaldehyde and the anti-inflammatory compound allopurinol was effective in attenuating fructose-induced oxidative stress and cardiac inflammation (Kang et al. 2016).

There is a strong support for the use of antioxidant vitamin-rich food in the diet for the management of metabolic syndrome (Bilbis et al. 2012). Another natural food with protective properties is betaine, which is found in wheat germ, bran and spinach, and seafood, especially marine invertebrates. Betaine has been shown to protect internal organs and improve vascular risk factors and can prevent chronic diseases (Craig 2004). High-fat meal increases oxidative stress (Devaraj et al. 2008) but a high-fiber rich meal improves endothelial function in subjects with metabolic syndrome (Brock et al. 2006). Dietary interventions with probiotics, through their antioxidant properties, are found to be a better option for the management of metabolic syndrome (Mallappa et al. 2012). 
AGEs, a class of dietary pro-oxidants that are abundant in thermally processed foods have received much attention in the pathophysiology of metabolic syndrome. It has been suggested that the increased consumption AGEs rich foods gradually leads to an excess of ROS, leading to inflammation, obesity, insulin resistance, and various diabetic complications (Farahmand et al. 2003; Vasdev et al. 2006; Vlassara and Striker 2011).

All these studies clearly emphasize the importance of oxidative stress in fructose-induced metabolic syndrome and its attenuation by targeting oxidative stress via antioxidants may play a major role in the dietary management of metabolic changes. Conditions such as insulin resistance, hypertension, hyperlipidemia, inflammation and endothelial dysfunction could be modulated by a dietary control of the progression of metabolic disease and its complications.

\section{Conclusions}

An alarming increase in fructose consumption may have significant influence on the epidemics of obesity and insulin resistant diabetes in both pediatric and adult populations. A high influx of fructose to the liver disturbs hepatic carbohydrate metabolism, leading to perturbations in glucose uptake pathways, culminating in a significant enhancement of lipogenesis and triglyceride synthesis. These metabolic disturbances appear to underlie the induction of insulin resistance, commonly observed with high fructose consumption in humans as well as animals (Basciano et al. 2005).

High consumption of fructose results in a considerable rise in the development of cardiometabolic dysfunction. Data from experimental as well as clinical trials suggest that high fructose consumption is an important causative factor in most of the components of metabolic syndrome associated with oxidative stress, hypertension and 
inflammation. Hence, one of the better regimens for the management of metabolic syndrome is to reduce fructose content in the diet. An important characterization of the population that consumes high levels of fructose is a subset of patients who are at increased risk of metabolic and cardiovascular complications. Future randomized clinical trials should be designed to address this important issue to reduce the cardiometabolic dysfunctions.

Moreover, multicenter studies are required to address important unanswered questions in the metabolic syndrome. Future research should further help to define the role of antioxidant supplementation to diet and exercise. A possible approach to reduce oxidative stress could be to inhibit ROS production by blocking pathways involved in its synthesis. This hypothesis suggests testing of novel molecules that could interfere in the production of free radicals and thus can reduce diseases caused by oxidative stress and inflammatory processes, such as metabolic syndrome.

On the other hand, genetic determinants are important players regarding the susceptibility to oxidative stress-induced risk factors for cardiometabolic dysfunctions. Their role in this condition is supported by familial clustering which would stimulate various studies dealing with changes in oxidative parameters and appearance of metabolic abnormalities. Future studies are required to examine susceptibility to the metabolic syndrome and its nutritional and genetic associations that would probably guide into targeted treatment and prevention strategies.

Impact of many dietary or lifestyle factors such as physical activity, caloric excess and weight gain have to be taken into account. Prevention through diet and physical activity is a strategy in retarding the progression of existing chronic diseases and decreasing mortality. 


\section{Acknowledgements}

Adriane Belló-Klein was a Visiting Professor; Nathalia Bernardes and Danielle da Silva Dias were exchange students from Brazil under the Canada-Brazil Training Program (CAPES-DFATD). Gauri Akolkar is the recipient of the Bank of Montreal studentship from the St. Boniface Hospital Foundation. Dr. Singal is the holder of the Dr. Naranjan S. Dhalla Chair in Cardiovascular Research supported by the St. Boniface Hospital Foundation. Supported by Canadian Institutes of Health Research (CIHR) and Research Manitoba. 


\section{References}

Abdilla, N., Tormo, M.C., Fabia, M.J., Chaves, F.J., Saez, G., and Redon, J. 2007. Impact of the components of metabolic syndrome on oxidative stress and enzymatic antioxidant activity in essential hypertension. J. Hum. Hypertens. 21:68-75. doi:10.1038/sj.jhh.1002105.

Alberti, K.G., Eckel, R.H., Grundy, S.M., Zimmet, P.Z., Cleeman, J.I., Donato, K.A. et al. 2009. Harmonizing the metabolic syndrome: A joint interim statement of the International Diabetes Federation Task Force on Epidemiology and Prevention; National Heart, Lung, and Blood Institute; American Heart Association; World Heart Federation; International Atherosclerosis Society; and International Association for the Study of Obesity. Circulation, 120:1640-1645. doi: 10.1161/CIRCULATIONAHA.109.192644.

Amaral, F., Lima, N.E.A., Ornelas, E., Simardi, L., Fonseca, Fla., and Maifrino, L.B.M. 2015. Effect of different exercise intensities on the pancreas of animals with metabolic syndrome. Diabetes, Metabol. Synd. Obesity: Targets Therapy. 8: 115-120. doi: https://doi.org/10.2147/DMSO.S74436.

Apovian, C.M., Bigornia, S., Mott, M., Meyers, Ulloor, J., and Gagua, M. 2008. Adipose macrophage infiltration is associated with insulin resistance and vascular endothelial dysfunction in obese subjects. Arterioscler. Thromb. Vasc. Biol. 28: 16541659. doi: 10.1161/ATVBAHA.108.170316.

Araujo, I.C., Andrade, R.P., Santos, F., Soares, E.S., Yokota, R., Mostarda, C., et al. 2016. Early developmental exposure to high fructose intake in rats with $\mathrm{NaCl}$ stimulation causes cardiac damage. Eur. J. Nutr. 55: 83-91. doi: 10.1007/s00394-0140826-5.

Arkan, M.C., Hevener, A.L., Greten, F.R., Maeda, S., Li, Z.W., Long, J.M., et al. 2005. IKK-beta links inflammation to obesity-induced insulin resistance. Nat. Med. 11: 191198. doi:10.1038/nm1185. 
Basciano, H., Federico, L., and Adeli, K. 2005. Fructose, insulin resistance, and metabolic dyslipidemia. Nutr. Metab. 2: 5. doi: 10.1186/1743-7075-2-5.

Beltran-Sanchez, H., Harhay, M.O., Harhay, M.m., and Mcelligott, S. 2013. Prevalence and trends of Metabolic Syndrome in the adult US population 1999-2010. J. Am. Coll. Cardiol. 62: 697-703. doi: 10.1016/j.jacc.2013.05.064.

Bezerra, R.M., Ueno, M., Silva, M.S., Tavares, D.Q., Carvalho, C.R., Saad, M.J., and Gontijo, J.A. 2001. A high-fructose diet induces insulin resistance but not blood pressure changes in normotensive rats. Braz. J. Med. Biol. Res. 34 (9):1155-60. PMID: 11514839

Bhatt, N.M., Chavda, M., Desai, D., Zalawadia, R., Patel, V.B., Burade, V., et al. 2012. Cardioprotective and antihypertensive effects of Enicostemma littorale Blume extract in fructose-fed rats. Can. J. Physiol. Pharmacol. 90: 1065-1073. doi: 10.1139/y2012-055.

Bigoniya, P., Nishad, R., and Singh, C.S. 2012. Preventive effect of sesame seed cake on hyperglycemia and obesity against high fructose-diet induced Type 2 diabetes in rats. Food Chem. 133: 1355-1361. http://dx.doi.org/10.1016/j.foodchem.2012.01.112.

Bilbis, L.S., Muhammad, S.A., Saidu, Y., and Adamu, Y. 2012. Effect of Vitamins A, $\mathrm{C}$, and $\mathrm{E}$ supplementation in the treatment of metabolic syndrome in albino rats. Biochem. Res. Int. 1-7, 2012. doi: 10.1155/2012/678582.

Boucher, J., Kleinridders, A, and Kahn, C.R. 2014. Insulin receptor signaling in normal and insulin-resistant states. Cold Spring Harb. Perspect. Biol. 6: a009191. doi: 10.1101/cshperspect.a009191.

Bray, G.A., Nielsen, S.J., and Popkin, B.M. 2004.Consumption of high-fructose corn syrup in beverages may play a role in the epidemic of obesity. Am. J. Clin. Nutr. 79: 537-43. PMID: 15051594. 
Brietzke, S.A. 2010. A personalized approach to metabolic aspects of obesity. Mt. Sinai J. Med. 77: 499-510.

Brito, J.O., Ponciano, K., Figueroa, D., Bernardes, N., Sanches, I.C., Irigoyen, M.C., and De Angelis, K. 2008. Parasympathetic dysfunction is associated with insulin resistance in fructose-fed female rats. Braz. J. Med. Biol. Res. 41: 804-808. PMID: 18833640

Brock, D.W., Davis, C.K., Irving, B.A., Rodriguez, J., Barrett, E.J., Weltman, A., et al. 2006. A high-carbohydrate, high-fiber meal improves endothelial function in adults with the metabolic syndrome. Diabetes Care, 29: 2313-2315. doi: 10.2337/dc06-0917.

Brown, C.M., Dulloo, A.J., Yepuri, G., and Montani, J.P. 2008. Fructose ingestion acutely elevates blood pressure in healthy young humans. Am. J. Physiol. Regul. Integr. Comp. Physiol. 294: R730-R737. doi: 10.1152/ajpregu.00680.2007.

Bryan, S., Baregzay, B., Spicer, D., Singal, P.K., and Khaper, N. 2013. Redoxinflammatory synergy in the metabolic syndrome. Can. J. Physiol. Pharmacol. 91: 2230. doi: 10.1139/cjpp-2012-0295.

Carr, D.B., Utzschneider, K.M., and Hull, R.L. 2004. Intra-abdominal fat is a major determinant of the National Cholesterol Education Program Adult Treatment Panel III criteria for the metabolic syndrome. Diabetes, 53: 2087-94. https://doi.org/10.2337/diabetes.53.8.2087.

Casini, A., Ceni, E., S., and alzano, R. 1997. Neutrophil-derived superoxide anion induces lipid peroxidation and stimulates collagen synthesis in human hepatic stellate cells: role of nitric oxide. Hepatology, 25: 361-7. doi:10.1053/jhep.1997.v25.pm0009021948.

Castro, E.F.S., Mostarda, C.T., Rodrigues, B., Moraes-Silva, I.C., Feriani, D.J., De Angelis. K., and Irigoyen, M.C. 2015. Exercise training prevents increased intraocular pressure and sympathetic vascular modulation in an experimental model of metabolic syndrome. Braz. J. Med. Biol. Res. 48: 332-338. doi: 10.1590/1414-431X20144217. 
Chabrashvili, T., Tojo, A., and Onozato, M.L. 2002. Expression and cellular localization of classic NADPH oxidase subunits in the spontaneously hypertensive rat kidney. Hypertension, 39: 269-74. https://doi.org/10.1161/hy0202.103264.

Cheng, P., Ho, W., Lu, Y., Chen, P., Cheng, B., Lu, W., et al. 2014. Resveratrol decreases fructose-induced oxidative stress, mediated by NADPH oxidase via an AMPK-dependent mechanism. Br. J. Pharmacol. 171: 2739-2750. doi: 10.1111/bph. 12648 .

Chien, K.Y., Huang, C.C., Hsu, K.F., Kuo, C.H., and Hsu., M.C. 2012. Swim training reduces metformin levels in fructose-induced insulin resistant rats. J. Pharm. Pharm. Sci. 15: 85-93. PMID: 22365090.

Chrousos., G.P. 1995. The hypothalamic-pituitary-adrenal axis and immunemediated inflammation. N. Engl. J. Med. 332: 1351-1362. doi:10.1056/NEJM199505183322008

Conti, F.F., Brito, J.O., Bernardes, N., Dias, D.S., Sanches. I.C., Malfitano, C., et al. 2014. Cardiovascular autonomic dysfunction and oxidative stress induced by fructose overload in an experimental model of hypertension and menopause. BMC Cardiovasc. Disorders, 14:185. doi: 10.1186/1471-2261-14-185.

Cook, S., Hugli, O., Egli, M., Vollenweider, P., Burcelin, R., Nicod, P., et al. 2003. Clustering of cardiovascular risk factors mimicking the human metabolic syndrome $\mathrm{X}$ in eNOS null mice. Swiss Med. Wkly. 133: 360-363. doi: 2003/25/smw-10239.

Corbaton-Anchuelo, A., Martínez-Larrad, M.T., Fernández-Pérez, C., Vega-Quiroga, S., Ibarra-Rueda, J.M., and Serrano-Ríos, M. 2013. Metabolic syndrome, adiponectin, and cardiovascular risk in Spain (The Segovia Study): impact of consensus societies criteria. Metab. Syndr. Relat. Disord. 11:309-318. doi: 10.1089/met.2012.0115.

Craig, S.A. Betaine in human nutrition. 2004. Am. J. Clin. Nutr. 80: 539-49. PMID: 15321791 . 
Crescenzo, R., Bianco, F., Falcone, I., Coppola, P., Liverini, G., and Iossa, S. 2013. Increased hepatic de novo lipogenesis and mitochondrial efficiency in a model of obesity induced by diets rich in fructose. Eur. J. Nutr. 52:537-45. DOI: 10.1007/s00394012-0356-y

Cunha, T.S., Farah. V., Paulini, J., Pazzine, M., Elased, K.M., and Marcondes, F.K. 2007. Relationship between renal and cardiovascular changes in a murine model of glucose intolerance. Regul. Pept. 139: 1-4. doi: 10.1016/j.regpep.2006.11.023

Dalen, K.T., Ulven, S.M., and Arntsen, B.M. 2006. PPARalpha activators and fasting induce the expression of adipose differentiation-related protein in liver. J. Lipid Res. 47: 931-43. doi: 10.1194/j1r.M500459-JLR200.

Dalleck, L.C., Guilder, Van. G.P., Richardson, T.B., and Vella, C.A. 2015. The prevalence of adverse cardiometabolic responses to exercise training with evidencebased practice is low. Diabetes Metab. Syndr. Obes. 8:73-8. doi: 10.2147/DMSO.S76880.

Daly, E. Vale, C., Walker, M., Alberti, K.G., and Mathers, J.C. 1997. Dietary carbohydrates and insulin sensitivity: a review of the evidence and clinical implications. Am. J. Clin. Nutr. 66: 1072-85. PMID: 9356523.

De Angelis, K., da Pureza, D.Y., Flores, L.J., Rodrigues, B., Melo, K.F., Schaan, B.D., and Irigoyen, M.C. 2006. Physiological effects of exercise training in patients with type 1 diabetes. Arq. Bras. Endocrinol. Metabol. 50: 1005-1013. PMID: 17221105.

De Angelis, K., Irigoyen, M.C., and Morris, M. 2009. Diabetes and cardiovascular autonomic dysfunction: application of animal models. Auton. Neurosci. 145: 3-10. doi: 10.1016/j.autneu.2008.10.013.

De Angelis, K., Senador, D.D., Mostarda, C., Irigoyen, M.C., and Morris M. 2012. Sympathetic overactivity precedes metabolic dysfunction in a fructose model of glucose 
intolerance in mice. Am. J. Physiol. Regul. Integr. Comp. Physiol. 302: R950-R957. doi: 10.1152/ajpregu.00450.2011.

D'Angelo, G., Elmarakby, A.A., Pollock, D.M., Stepp, D.W. 2005. Fructose feeding increases insulin resistance but not blood pressure in Sprague-Dawley rats. Hypertension, 46 (4): 806-11. doi: 10.1161/01.HYP.0000182697.39687.34.

Deedwania, P.C. 2003. Mechanisms of endothelial dysfunction in the metabolic syndrome. Curr. Diab. Rep. 3: 289-292. PMID: 12866990

Delbosc, S., Paizanis, E., Magous, R., Araiz, C., Dimo, T., Cristol, J.P., et al. 2005. Involvement of oxidative stress and NADPH oxidase activation in the development of cardiovascular complications in a model of insulin resistance, the fructose-fed rat. Atherosclerosis. 179: 43-9. doi: 10.1016/j.atherosclerosis.2004.10.018

Demirbag, R., Yilmaz, R., Gur, M., Celik, H., Guzel, S., and Selek, S. 2006. DNA damage in metabolic syndrome and its association with antioxidative and oxidative measurements. Int. J. Clin. Pract. 60:1187-93. doi:10.1111/j.1742-1241.2006.01042.x.

Demircan, N., Gurel, A., Armuctu, F., Unalacak, M., Aktunc, and Atmaca, H. 2008. The evaluation of serum cystatin $\mathrm{C}$, malonildialdehyde and total antioxidant status in patients with metabolic syndrome. Med. Sci. Monit. 14: 97-101. PMID:18227768

Despres, J.P., Lemieux, I., Bergeron, J., Pibarot, P., Mathieu, P., Larose, E., et al. 2008. Abdominal obesity and the metabolic syndrome: contribution to global cardiometabolic risk. Arterioscler. Thromb. Vasc. Biol. 28: 1039-1049. doi: 10.1161/ATVBAHA.107.159228

Devaraj, S.,Wang-Polagruto, J., Polagruto, J., Keen, C.L., and Jialal, I.B. 2008. Highfat, energy-dense, fastfood-style breakfast results in an increase in oxidative stress in metabolicsyndrome. Metabolism. 57: 867-870. doi:10.1016/j.metabol.2008.02.016

Dhingra, R., Sullivan, L., Jacques, P.F, Wang, T.J., Fox, C.S., Meigs, J.B., et al. 2007. Soft drink consumption and risk of developing cardiometabolic risk factors and the 
metabolic syndrome in middle-aged adults in the community. Circulation, 116: 480488. doi:10.1161/CIRCULATIONAHA.107.689935.

Dhingra, S., Sharma, A.K., Arora, R.C., Slezak, J., and Singal, P.K. 2009. IL-10 attenuates TNF-alpha-induced NF-kappaB pathway activation and cardiomyocyte apoptosis. Cardiovasc. Res. 82: 59-66. doi: 10.1093/cvr/cvp040.

Diehl, A.M. 2004. Tumor necrosis factor and its potential role in insulin resistance and nonalcoholic fatty liver disease. Clin. Liver Dis. 8: 619-38. doi: 10.1016/j.cld.2004.04.012.

Dixon, J.B., Bhathal, P.S., Hughes, N.R., and O'brien, P.E. 2004. Nonalcoholic fatty liver disease: improvement in liver histological analysis with weight loss. Hepatology. 39: 647-1654. doi: 10.1002/hep.20251.

Donath, M.Y., and Shoelson, S.E. 2011. Type 2 diabetes as an inflammatory disease. Nat. Rev. Immunol. 11: 98-107. doi: 10.1038/nri2925.

Dokken, B.B. 2008. The Pathophysiology of Cardiovascular Disease and Diabetes: Beyond Blood Pressure and Lipids. Diabetes Spectrum. 21 (3): 160-165. https://doi.org/10.2337/diaspect.21.3.160.

Egli, L., Lecoultre, V., Cros, J., Rosset, R., Marques, A.S., Schneiter, P., et al. 2016. Exercise performed immediately after fructose ingestion enhances fructose oxidation and suppresses fructose storage. Am. J. Clin. Nutr. 103: 348-55. doi:10.3945/ajen.115.116988.

Eiserich, J.P., Hristova, M., and Cross, C.E. 1998a. Formation of nitric oxide-derived inflammatory oxidants by myeloperoxidase in neutrophils. Nature. 7: 391-393. doi: $10.1038 / 34923$.

Eiserich, J.P., Patel, R.P., and O'donnell, V.B. 1998b. Pathophysiology of nitric oxide and related species: free radical reactions and modification of biomolecules. Mol. Aspects. Med. 19: 221-357. PMID: 10231805. 
Elliott, S.S., Keim, N.L., Stern, J.S., Teff, K., and Havel, P.J. 2002. Fructose, weight gain, and the insulin resistance syndrome. Am. J. Clin. Nutr. 76: 911-922. PMID: 12399260.

Escobedo, J., Schargrodsky, H., Champagne, B., Silva, H., Boissonnet, C., Vinueza, R., et al. 2009. Prevalence of the metabolic syndrome in Latin America and its association with sub-clinical carotid atherosclerosis: the CARMELA cross sectional study. Cardiovasc. Diabetol. 8: 52. doi: 10.1186/1475-2840-8-52. doi: 10.1186/1475-2840-852.

Esler, M. 2000. The sympathetic system and hypertension. Am. J. Hypertens. 13: 99S105S. PMID: 10921528

Farah, V., Elased, K.M., Chen, Y., Key, M.P., Cunha, T.S., and Irigoyen, M.C. 2006. Nocturnal hypertension in mice consuming a high fructose diet. Auton. Neurosci. 130: 41-50. doi: 10.1016/j.autneu.2006.05.006.

Farahmand, F., Lou, H., and Singal, P.K. 2003. Oxidative stress in cardiovascular complications of diabetes. Atherosclerosis, Hypertension and Diabetes. Edited by: G. N. Pierce, M. Nagano, P. Zahradka, and N. S. Dhalla. Kluwer Academic Publishers, Boston, USA, 427-437. Doi: 10.1007/978-1-4419-9232-1_32

Feig, D.I., Soletsky, B., and Johnson, R.J. 2008. Effect of allopurinol on blood pressure of adolescents with newly diagnosed essential hypertension: A randomized trial. JAMA. 300: 924-932. doi:10.1001/jama.300.8.924

Feskens, E.J., Virtanen, S.M., Rasanen, L., Tuomilehto, J., Stengård, J., Pekkanen, J., et al. 1995. Dietary factors determining diabetes and impaired glucose tolerance: A 20year follow-up of the Finnish and Dutch cohorts of the Seven Countries Study. Diabetes Care, 18: 1104-1112. https://doi.org/10.2337/diacare.18.8.1104.

Feskens, E.J., and Kromhout, D. 1990. Habitual dietary intake and glucose tolerance in euglycaemic men: the Zutphen Study. Int. J. Epidemiol. 19: 953-959. PMID: 2084027. 
Festa, A., D’agostino, R., Howard, G., Mykkanen, L., Tracy, R.P., and Haffner, S.M. 2000. Chronic subclinical inflammation as part of the insulin resistance syndrome: the Insulin Resistance Atherosclerosis Study (IRAS). Circulation, 102:42-47. https://doi.org/10.1161/01.CIR.102.1.42.

Fito, M., Cladellas, M., de la Torre R., Martí, J., Alcántara, M., Pujadas-Bastardes, M., Marrugat, J., et al. 2005. Antioxidant effect of virgin olive oil in patients with stable coronary heart disease: a randomized, crossover, controlled, clinical trial. Atherosclerosis, 181: 149-58. doi: 10.1016/j.atherosclerosis.2004.12.036.

Fonseca, M.J., Gaio, R., Lopes, C., and Santos, A.C. 2012. Association between dietary patterns and metabolic syndrome in a sample of Portuguese adults. Nutr. J. 11: 64. doi: 10.1186/1475-2891-11-64.

Forman, J.P., Choi, H., and Curhan, G.C. 2009. Fructose and vitamin C intake do not influence risk for developing hypertension. J. Am. Soc. Nephrol. 20: 863-871. doi: 10.1681/ASN.2008050473.

Fujita, K., Nishizawa, H., Funahashi, T., Shimomura, I., and Shimabukuro, M. 2006. Systemic oxidative stress is associated with visceral fat accumulation and the metabolic syndrome. Circ. J. 70: 1437-42. PMID: 17062967.

Furukawa, S., Fujita, T., and Shimabukuro, M. 2004. Increased oxidative stress in obesity and its impact on metabolic syndrome. J. Clin. Invest. 114: 1752-61. doi: $10.1172 / \mathrm{JCI} 21625$.

Gao, B., Qi, L., Qiao, N., Choi, H.K., Curhan, G., Tucker, K.L., and Ascherio A. 2007. Intake of added sugar and sugar-sweetened drink and serum uric acid concentration in US men and women. Hypertension, 50: 306-312. doi:10.1161/HYPERTENSIONAHA.107.091041.

Giacchetti, G., Sechi, L.A., Griffin, C.A., Don, B.R., Mantero, F., and Schambelan, M. 2000. The tissue renin-angiotensin system in rats with fructose-induced hypertension: 
overexpression of type 1 angiotensin II receptor in adipose tissue. J. Hypertens. 18: 695702. PMID:10872553.

Girona, J., Manzanares, J.M., Marimon, F., Cabre, A., Heras, M., and Guardiola, M. 2007. Oxidized to non-oxidized lipoprotein ratios are associated with arteriosclerosis and the metabolic syndrome in diabetic patients. Nutr. Metab. Cardiovasc. Dis. 18: 380387. doi: 10.1016/j.numecd.2007.04.002.

Glushakova, O., Kosugi, T., Roncal, C., Mu, W., Heinig, M., Cirillo, P., et al. 2008. Fructose induces the inflammatory molecule ICAM-1 in endothelial cells. J. Am. Soc. Nephrol. 19: 1712-1720. doi: 10.1681/ASN.2007121304.

Grattagliano, I., Palmieri, Vo., Portincasa, P., Moschetta, A., and Palasciano, G. 2008. Oxidative stress-induced risk factors associated with the metabolic syndrome: a unifying hypothesis. J. Nutr. Biochem. 19: 491-504. doi:10.1016/j.jnutbio.2007.06.011.

Grattagliano, I., Vendemiale, G., Boscia, F., Micelli-Ferrari, T., Cardia, L., and Altomare, E. 1998. Oxidative retinal products and ocular damages in diabetic patients. Free Radic. Biol. Med. 25: 369-72. PMID:9680184.

Grattagliano, I., Vendemiale, G., Caraceni, P., Domenicali, M., Nardo B., Cavallari, A., et al. 2000. Starvation impairs antioxidant defense in fatty livers of rats fed a choline deficient diet. J. Nutr. 130: 2131-6. PMID:10958803

Guglielmotto, M., Aragno, M., Tamagno, E., Vercellinatto, I., Visentin, S., Medana, C. etal. 2012. AGEs/RAGE complex upregulates BACE1 via NF-kappaB pathway activation. Neurobiol. Aging, 33: 196, e113-e127. doi: 10.1016/j.neurobiolaging.2010.05.026.

Haffner, S.M., Valdez, R.A., Hazuda, H.P., Mitchell, B.D., Morales, P.A., and Stern, M.P. 1992. Prospective analysis of the insulin-resistance syndrome (syndrome X). Diabetes, 41:715-22. PMID: 1587398. 
Hallfrisch, J. 1990. Metabolic effects of dietary fructose. FASEB J. 4: 2652-2660. PMID:2189777.

Halliwell, B. 1997. What nitrates tyrosine? Is nitrotyrosine specific as a biomarker of peroxynitrite formation in vivo? FEBS Lett. 60: 411-157. PMID:9271196.

Hansson, G.K., and Libby, P. 2006. The immune response in atherosclerosis: a doubleedged sword. Nat. Rev. Immunol. 6: 508-519. doi:10.1038/nri1882.

Henriksen, E.J., Diamond-Stanic, M.K., and Marchionne, E.M. 2011. Oxidative stress and the etiology of insulin resistance and type 2 diabetes. Free Radic. Biol. Med. 51: 993-999. doi:10.1016/j.freeradbiomed.2010.12.005.

Hokayem, M., Blond, E., Vidal, H., Lambert, K., Meugnier, E., Feillet-Coudray, C., et al. 2013. Grape polyphenols prevent fructose-induced oxidative stress and insulin resistance in first-degree relatives of type 2 diabetic patients. Diabetes Care. 36:145461. doi:10.2337/dc12-1652.

Hopps, E., Noto, D., Caimi, G., and Averna, M.R. 2010. A novel component of the metabolic syndrome: The oxidative stress. Nutr. Metab. Cardiovasc. Dis. 20:72-77. doi: 10.1016/j.numecd.2009.06.002.

Hosogai, N., Fukuhara, A., Oshima, K., Miyata, Y., Tanaka, S., Segawa, K., et al. 2007. Adipose tissue hypoxia in obesity and its impact on adipocytokine dysregulation. Diabetes, 56: 901-911. doi: 10.2337/db06-0911.

Hotamisligil, G.S. 1999. Mechanisms of TNF-alpha-induced insulin resistance. Exp. Clin. Endocrinol. Diabetes, 107: 119-125. doi:10.1055/s-0029-1212086.

Hozayen, W.G., Mahmoud, A.M., Soliman, H.A., and Mostafa, S.R. 2016. Spirulina versicolor improves insulin sensitivity and attenuates hyperglycemia-mediated oxidative stress in fructose-fed rats. J. Intercult. Ethnopharmacol. 5: 57-64. doi: $10.5455 /$ jice. 20151230055930 . 
Hu, G., Qiao, Q., Tuomilehto, J., Eliasson M., Feskens, E.J., Pyorala K., et al. 2004. Plasma insulin and cardiovascular mortality in non-diabetic European men and women: a meta-analysis of data from eleven prospective studies. Diabetologia, 47: 1245-56. doi: 10.1007/s00125-004-1433-4.

Hulsmans, M., De Keyzer, D., and Holvoet, P. 2011. MicroRNAs regulating oxidative stress and inflammation in relation to obesity and atherosclerosis. FASEB J. 25: 25152527. doi: 10.1096/fj.11-181149.

Hulsmans, M., Van Dooren, E., and Holvoet, P. 2012. Mitochondrial reactive oxygen species and risk of atherosclerosis. Curr. Atheroscler. Rep. 14:264-276. doi: 10.1007/s11883-012-0237-0.

Hwang, S. Ho. H., Hoffman, B.B., and Reaven, G.M. 1987. Fructose-induced insulin resistance and hypertension in rats. Hypertension, 10: 512-516. PMID: 3311990.

Ivy, J.L. 1997. Role of exercise training in the prevention and treatment of insulin resistance and non-insulin-dependent diabetes mellitus. Sports Med. 24. 321-36. PMID: 9368278.

Jaiswal, N., Maurya, C.K., Arha, D., Avisetti, Prathapan, A., Raj, P.S., et al. 2015. Fructose induces mitochondrial dysfunction and triggers apoptosis in skeletal muscle cells by provoking oxidative stress. Apoptosis, 20: 930-947. doi: 10.1007/s10495-0151128-y.

Jalal, D.I., Smits, G., Johnson, R.J., and Chonchol, M. 2010. Increased fructose associates with elevated blood pressure. J. Am. Soc. Nephrol. 21: 1543-1549. doi: 10.1681/ASN.2009111111.

Johnson, R.J., Nakagawa, T., Sanchez-Lozada, L.G., Shafiu, M., Sundaram, S., Le, M., et al. 2013. Sugar, uric acid, and the etiology of diabetes and obesity. Diabetes, 62:3307-3315. doi: 10.2337/db12-1814. 
Jossa, F., Farinaro, E., Panico, S., Krogh, V., Celentano, E., Galasso, R., et al. 1994. Serum uric acid and hypertension: the Olivetti heart study. J. Hum. Hypertens. 8: 677681. PMID:7807497.

Kamide, K., Rakugi, H., Higaki, J., Okamura, A., Nagai, M., Moriguchi, K., et al. 2002. The renin-angiotensin and adrenergic nervous system in cardiac hypertrophy in fructose-fed rats. Am. J. Hypertens. 15: 66-67. PMID: 11824863.

Kaneto, H., Fujii, J., Myint, T., Miyazawa, N., Islam, K.N., Kawasaki, Y. et al. 1996. Reducing sugars trigger oxidative modification and apoptosis in pancreatic beta-cells by provoking oxidative stress through the glycation reaction. Biochem. J. 320: 855-863. PMID: 9003372

Kang, L., Zhang, D., Ma, C., Zhang, J., Jia, K., Liu, J., et al. 2016. Cinnamaldehyde and allopurinol reduce fructose-induced cardiac inflammation and fibrosis by attenuating CD36-mediated TLR4/6-IRAK4/1 signaling to suppress NLRP3 inflammasome activation. Sci. Rep. 6:27460.

Kassi, E., Pervanidou, P., Kaltsas, G., and Chrousos, G. 2011. Metabolic syndrome: definitions and controversies. BMC Med. 9: 48. doi: 10.1186/1741-7015-9-48.

Katzmarzyk, P.T., Church, T.S., and Blair, S.N. 2004. Cardiorespiratory fitness attenuates the effects of the metabolic syndrome on all-cause and cardiovascular disease mortality in men. Arch. Intern. Med. 164: 1092-1097. doi: 10.1001/archinte.164.10.1092.

Kawanishi, N., Yano, H., Mizokami, T., Takahashi, M., Oyanagi, E., and Suzuki, K. 2012. Exercise training attenuates hepatic inflammation, fibrosis and macrophage infiltration during diet induced-obesity in mice. Brain Behav. Immun. 26: 931-41. DOI: 10.1016/j.bbi.2012.04.006.

Khaper, N., Bryan, S., Dhingra, S., Singal, R., Bajaj, A., Pathak, C.M., and Singal, P.K. 2010. Targeting the vicious inflammation-oxidative stress cycle for the management of heart failure. Antioxid. Redox. Signal. 13: 1033-1049. doi: 10.1089/ars.2009.2930. 
Khosla, U.M., Zharikov, S., Finch, J.I., Nakagawa, T., Roncal, C., Mu, W., et al. 2005. Hyperuricemia induces endothelial dysfunction. Kidney Int. 67: 1739-1742. doi: 10.1111/j.1523-1755.2005.00273.x.

Lacoviello, L., Bonanni, A., Costanzo, S., De Curtis, A., Di Castelnuovo, A., Olivieri, M., et al. 2007. The Moli-Sani project, a randomized, prospective cohort study in the Molise region in Italy; design, rationale and objectives. Ital. J. Public Health, 4:110-118. doi: http://dx.doi.org/10.2427/5886.

Lakka, T.A., Laaksonen, D.E., Lakka, H.M., Mannikko, N., Niskanen, L.K., Rauramaa R., and Salonen JT. 2003. Sedentary lifestyle, poor cardiorespiratory fitness, and the metabolic syndrome. Med. Sci. Sports Exerc. 35: 1279-1286. doi: 10.1249/01.MSS.0000079076.74931.9A.

Landmesser, U., Dikalov, S., Price, S.R., McCann, L., Fukai, T., Holland, S.M., et al. 2003. Oxidation of tetrahydrobiopterin leads to uncoupling of endothelial cell nitric oxide synthase in hypertension. J. Clin. Invest. 9: 111-1201. doi:10.1172/JCI14172.

Lastra, G., Habibi, J., Whaley-Connell, A.T., Manrique, C., Hayden, M.R., Rehmer, J., et al. 2009. Direct renin inhibition improves systemic insulin resistance and skeletal muscle glucose transport in a transgenic rodent model of tissue renin overexpression. Endocrinology, 150: 2561-2568. doi: 10.1210/en.2008-1391.

Lau, D.CW., Dhillon, B., Yan, H., Szmitko, P.E., and Verma, S. 2005. Adipokines: molecular links between obesity and atherosclerosis. Am. J. Physiol. Heart Circ. Physiol. 288: H2031-H2041. doi: 10.1152/ajpheart.01058.2004.

Laville, M., and Nazare, J.A. 2009. Diabetes, insulin resistance and sugars. Obes. Rev. 10: 24-33. doi: 10.1111/j.1467-789X.2008.00562.x.

Libby, P., Ridker, P.M., and Maseri, A. 2002. Inflammation and atherosclerosis. Circulation, 105: 1135-1143. https://doi.org/10.1161/hc0902.104353. 
Lipton, S.A., Choi, Y.B., Pan, Z.H., Lei, S.Z., Chen, H.S., Sucher, N.J., et al. 1993. A redox-based mechanism for the neuroprotective and neurodestructive effects of nitric oxide and related nitroso-compounds. Nature, 364: 626-32. DOI: 10.1038/364626a0.

Liu, S., and Manson, J. 2001. Dietary carbohydrates, physical inactivity, obesity, and the 'metabolic syndrome' as predictors of coronary heart disease. Curr. Opin. Lipidol. 12: 395-404. PMID:11507324

Liu, S., and Willett, W.C. 2002. Dietary glycemic load and atherothrombotic risk. Curr. Atheroscler. Rep. 4: 454-461. doi: 10.1007/s11883-002-0050-2.

Livesey, G., and Taylor, R. 2008. Fructose consumption and consequences for glycation, plasma triacylglycerol, and body weight: meta-analyses and meta-regression models of intervention studies. Am. J. Clin. Nutr. 88: 1419-37. PMID:18996880.

Lustig, R.H., Schmidt, L.A., and Brindis, C.D. 2012. Excessive consumption of fructose can cause many of the same health problems as alcohol. Nature, 482: 27-29.

Machi, J.F., Bernardes, N., Mostarda, C., Moraes-Silva, I.C., Irigoyen, M.C., De Angelis, K., and Wichi, R.B. 2013. Walking promotes metabolic and baroreflex sensitivity improvement in fructose-fed male rats. Eur. J. Appl. Physiol. 113: 41-9. doi: 10.1007/s00421-012-2411-z.

Malik, V.S., Popkin, B.M., Bray, G.A., Despres, J.P., Willett, W.C., and Hu, F.B. 2010. Sugar-Sweetened Beverages and Risk of Metabolic Syndrome and Type 2 Diabetes. Diabetes Care, 33: 2477-2483. https://doi.org/10.2337/dc10-1079.

Mallappa, R.H., Rokana, N., Duary, R.K., Panwar, H., Batish, V.K., and Grover, S. 2012. Management of metabolic syndrome through probiotic and prebiotic interventions. Indian J. Endocrinol. Metab. 16:20-27, 2012. doi: 10.4103/22308210.91178 . 
Mazzali, M. Hughes, J., Kim, Y.G., Jefferson, J.A., Kang, D.H., Gordon, K.L., et al. 2001. Elevated uric acid increases blood pressure in the rat by a novel crystal independent mechanism. Hypertension, 38: 1101-1106. PMID:11711505.

Miller, A., and Adeli, K. 2008. Dietary fructose and the metabolic syndrome. Curr. Opin. Gastroenterol. 24: 204-9. doi: 10.1097/MOG.0b013e3282f3f4c4.

Minamino, T., Orimo, M., Shimizu, I., Kunieda, T., Yokoyama, M., Ito, T., et al. 2009. A crucial role for adipose tissue p53 in the regulation of insulin resistance. Nat. Med. 15: 1082-1087. doi:10.1038/nm.2014.

Mohamed-Ali, V., K. Bulmer, D. Clarke, Goodrick, S., Coppack, S.W., Pinkney, J.H. 2000. $\beta$-adrenergic regulation of proinflammatory cytokines in humans. Int. J. Obes. Relat. Metab. Disord. 24: S154-S155. PMID:10997642

Moore, J.B., Gunn, P.J., and Fielding, B.A. 2014. The role of dietary sugars and de novo lipogenesis in non-alcoholic fatty liver disease. Nutrients. 6:5679-5703. doi: $10.3390 /$ nu6125679.

Moraes-Silva, I.C., De La Fuente, R.N., Mostarda, C., Rosa, K., Flues, K., DamacenoRodrigues, N.R., et al. 2010. Baroreflex deficit blunts exercise training-induced cardiovascular and autonomic adaptations in hypertensive rats. Clin. Exp. Pharmacol. Physiol. 37: e114-e120. doi:10.1111/j.1440-1681.2009.05333.x.

Moraes-Silva, I.C., Mostarda, C., Moreira, E.D., Silva, K.A., dos Santos, F., De Angelis, K., et al. 2013. Preventive role of exercise training in autonomic, hemodynamic, and metabolic parameters in rats under high risk of metabolic syndrome development. J. Appl. Physiol. 114: 786-791. doi: 10.1152/japplphysiol.00586.2012.

Morvan, E., Lima, N.E., Machi, J.F., Mostarda, C., de Angelis, K., Irigoyen, M.C., et al. 2013. Metabolic, hemodynamic and structural adjustments to low intensity exercise training in a metabolic syndrome model. Cardiovasc. Diabetol. 12: 1-10. doi: $10.1186 / 1475-2840-12-89$. 
Mostarda, C., Moraes-Silva, I.C., Salemi, V.M., Machi, J.F., Rodrigues, B., de Angelis, K., 2012. Exercise training prevents diastolic dysfunction induced by metabolic syndrome in rats. Clinics, 67: 815-820. doi: 10.6061/clinics/2012(07)18.

Mostarda, C.T., Rodrigues, B., de Moraes, O.A., Moraes-Silva, I.C., Arruda, P.B., Cardoso, R., et al. 2014. Low intensity resistance training improves systolic function and cardiovascular autonomic control in diabetic rats. J. Diabetes Complications, 28: 273-8. doi: 10.1016/j.jdiacomp.2013.12.005.

Murakami, T., Shimomura, Y., Fujitsuka, N., Sokabe, M., Okamura, K., and Sakamoto, S. 1997. Enlargement of glycogen store in rat liver and muscle by fructose-diet intake and exercise training. J. Appl. Physiol. 82:772-775. PMID:9074962

Myers, P.R., Minor, R.L. Jr., Guerra, R.Jr., Bates, J.N., and Harrison, D. G. 1990. Vasorelaxant properties of the endothelium-derived relaxing factor more closely resemble S-nitrosocysteine than nitric oxide. Nature, 345: 161-3. doi:10.1038/345161a0.

Nakagawa, T., Hu, H., Zharikov, S., Tuttle, K.R., Short, R.A., Glushakova, O., et al. 2006. A causal role for uric acid in fructose-induced metabolic syndrome. Am. J. Physiol. Renal. Physiol. 290: F625-F631. doi: 10.1152/ajprenal.00140.2005.

Nakagawa, T., Tuttle, K.R., Short, R.A., and Johnson, R.J. 2005. Hypothesis: fructoseinduced hyperuricemia as a causal mechanism for the epidemic of the metabolic syndrome. Nat. Clin. Pract. Nephrol. 1: 80-86. doi:10.1038/ncpneph0019.

Nettleton, J.A., Lutsey, P.L., Wang, Y., Lima, J.A., Michos, E.D., and Jacobs, D.R. Jr. 2009. Diet soda intake and risk of incident metabolic syndrome and type 2 diabetes in the Multi-Ethnic Study of Atherosclerosis (MESA). Diabetes Care, 32: 688-694. doi: $10.2337 / \mathrm{dc} 08-1799$.

Nguyen, S., Choi, H.K., Lustig, R.H., and Hsu, C. 2009. Sugar-sweetened beverages, serum uric acid, and blood pressure in adolescents. J. Pediatr. 154: 807-813. doi: 10.1016/j.jpeds.2009.01.015. 
Ouchi, N., Parker, J.L., Lugus, J.J. Walsh, K. 2011. Adipokines in inflammation and metabolic disease. Nat. Rev. Immunol. 11: 85-97. doi:10.1038/nri2921

Page, S., Chandhoke, V., and Baranova, A. 2011. Melanin and melanogenesis in adipose tissue: possible mechanisms for abating oxidative stress and inflammation? Obes. Rev. 12: e21-e31. doi:10.1111/j.1467-789X.2010.00773.x

Palmieri, V.O., Grattagliano, I., Portincasa, P., and Palasciano, G. 2006. Systemic oxidative alterations are associated with visceral adiposity and liver steatosis in patients with metabolic syndrome. J. Nutr. 136: 3022-3026. PMID:17116714.

Paravicini, T.M., and Touyz, R.M. 2006. Redox signaling in hypertension. Cardiovasc. Res. 71: 247-258. doi:10.1016/j.cardiores.2006.05.001.

Parise, G., Brose, A.N., and Tarnopolsky, M.A. 2005. Resistance exercise training decreases oxidative damage to DNA and increases cytochrome oxidase activity in older adults. Exp. Gerontol. 40: 173-180. doi:10.1016/j.exger.2004.09.002.

Parker, D.R., Weiss, S.T., Troisi, R., Cassano, P.A., Vokonas, P.S., and Landsberg, L.1993. Relationship of dietary saturated fatty acids and body habitus to serum insulin concentrations: the Normative Aging Study. Am. J. Clin. Nutr. 58: 129-136. PMID: 8338037.

Pattyn, N., Cornelissen, V.A., Eshghi, S.R., and Vanhees, L. 2013. The effect of exercise on the cardiovascular risk factors constituting the metabolic syndrome: a metaanalysis of controlled trials. Sports Med. 43: 121-33. doi: 10.1007/s40279-012-0003-z.

Paukku, K., and Silvennoinen, O. 2004. STATs as critical mediators of signal transduction and transcription: lessons learned from STAT5. Cytokine and Growth Factor Rev. 15: 435-455. doi:10.1016/j.cytogfr.2004.09.001.

Paulino, E.C., Ferreira, J.C., Bechara, L.R., Tsutsui, J.M., Mathias, W. Jr., Lima, F.B., et al. 2010. Exercise training and caloric restriction prevent reduction in cardiac $\mathrm{Ca}^{2+}$ - 
handling protein profile in obese rats. Hypertension, 56: 629-635. doi: 10.1161/HYPERTENSIONAHA.110.156141.

Perez-Pozo, S.E., Schold, J., Nakagawa, T., Sanchez-Lozada, L.G., Johnson, R.J., and Lillo, J.L. 2010. Excessive fructose intake induces the features of metabolic syndrome in healthy adult men: role of uric acid in the hypertensive response. Int. J. Obes. (Lond) 34: 454-46. doi:10.1038/ijo.2009.259

Pitsavos, C., Panagiotakos, D.B., Chrysohoou, C., Skoumas, J., Papaioannou, I., Stefanadis, C., and Toutouzas, P.K. 2002. The effect of Mediterranean diet on the risk of the development of acute coronary syndromes in hypercholesterolemic people: a case-control study (CARDIO2000). Coron. Artery Dis. 13: 295-300. PMID:12394655

Quinteiro, H., Buzin, M., Conti, F.F., Dias, D.S., Figueroa, D., Llesuy, S., et al. 2015. Aerobic exercise training promotes additional cardiac benefits better than resistance exercise training in postmenopausal rats with diabetes. Menopause. 22: 534-541. doi: 10.1097/GME.0000000000000344.

Rabkin, S.W. 2009. The role of interleukin 18 in the pathogenesis of hypertensioninduced vascular disease. Nat. Clin. Pract. Cardiovasc. Med. 6: 192-199. doi: 10.1038/ncpcardio1453.

Reaven, G.M. 2011. The metabolic syndrome: time to get off the merry-go-round? J. Intern. Med. 269: 127-136. doi:10.1111/j.1365-2796.2010.02325.x

Rector, R.S., Warner, S.O., Liu, Y., Hinton, P.S., Sun, G.Y., Cox, R.H., et al. 2007. Exercise and diet induced weight loss improves measures of oxidative stress and insulin sensitivity in adults with characteristics of the metabolic syndrome. Am. J. Physiol. Endocrinol. Metabol. 293: E500-506. doi:10.1152/ajpendo.00116.2007.

Reiser, S. 1985. Effects of dietary sugars in metabolic risk factors associated with heart disease. Nutr. Health, 3: 203-16. PMID:3906452 
Renna, N.F., Lembo, C., Diez, E., and Miatello, R.M. 2013. Role of renin-angiotensin system and oxidative stress on vascular inflammation in insulin resistence model. Int. J. Hypertension, 2013. doi.org/10.1155/2013/420979

Ridker, P.M., Buring, J.E., Cook, N.R., and Rifai, N. 2003. C-reactive protein, the metabolic syndrome, and risk of incident cardiovascular events: an 8-year follow-up of 14,719 initially healthy American women. Circulation, 107: 391-397. PMID:12551861

Roberts, C.K., Barnard, R.J., Sindhu, R.K., Jurczak, M., Ehdaie, A., and Vaziri, N.D. 2006b. Oxidative stress and dysregulation of NADP(H) oxidase and antioxidant enzymes in diet-induced metabolic syndrome. Metabolism, 55: 928-34. doi:10.1016/j.metabol.2006.02.022.

Roberts, C.K., and Barnard, R.J. 2005. Effects of exercise and diet on chronic disease. J. Appl. Physiol. 98: 3-30. doi:10.1152/japplphysiol.00852.2004.

Roberts, C.K., Ng, C., Hama, S., Eliseo, A.J., and Barnard, R.J. 2006c. Effect of a shortterm diet and exercise intervention on inflammatory/anti-inflammatory properties of HDL in overweight/obese men with cardiovascular risk factors. J. Appl. Physiol. 101: 1727-1732. doi:10.1152/japplphysiol.00345.2006.

Roberts, C.K., and Sindhu, K.K. 2009. Oxidative stress and metabolic syndrome. Life Sci. 84: 705-712. doi: 10.1016/j.lfs.2009.02.026.

Roberts, C.K., Vaziri, N.D., and Barnard, R.J. 2002. Effect of diet and exercise intervention on blood pressure, insulin, oxidative stress, and nitric oxide availability. Circulation, 106: 2530-2532. PMID: 12427646

Roberts, C. K., Vaziri, N.D., Wang, X.Q, and Barnard, R.J. 2000. NO inactivation and hypertension induced by a high-fat, refined-carbohydrate diet. Hypertension, 36: 423-9. PMID:10988276.

Roberts, C.K., Won, D., Pruthi, S., Kurtovic, S., Sindhu, R., Vaziri, N., and Barnard, R.A. 2006a. Effect of a short-term diet and exercise intervention on oxidative stress, 
inflammation, MMP-9, and monocyte chemotactic activity in men with metabolic $\begin{array}{lllll}\text { syndrome factors. } & \text { J. Appl. Physiol. 100: 1657-1665. }\end{array}$ doi:10.1152/japplphysiol.01292.2005.

Rocchini, A.P., Yang, J.Q., Smith, M.J., and Supiano, M.A. 2010. Serial changes in norepinephrine kinetics associated with feeding dogs a high-fat diet. J. Clin. Hypertens. 12:117-124. doi:10.1111/j.1751-7176.2009.00230.x.

Rodriguez-Itrube, B., Vaziri, N.D., Herrera, J., and Johnson, R.J. 2004. Oxidative stress, renal infiltration of immune cells and salt-sensitive hypertension: all for one and one or all. Am. J. Physiol. Renal. Physiol. 286:F606- F616. doi:10.1152/ajprenal.00269.2003

Ross, R. 1999. Atherosclerosis-an inflammatory disease. N. Engl. J. Med. 340: 115-126. doi:10.1056/NEJM199901143400207.

Roy, D., Perreault, M., and Marette, A. 1998. Insulin stimulation of glucose uptake in skeletal muscles and adipose tissues in vivo is NO dependent. Am. J. Physiol. Endocrinol. Metab. 274: E692-E699. PMID:9575831.

Sakr, H.F. 2013. Modulation of metabolic and cardiac dysfunctions by swimming in overweight rats on a high cholesterol and fructose diet: possible role of adiponectin. J. Physiol. Pharmacol. 64: 231-40. PMID:23756398.

Sanches, I.C., Brito, J.O., Candido, G.O., Dias, D.S., Jorge, L., Irigoyen, M.C., and De Angelis, K. 2012. Cardiometabolic benefits of exercise training in an experimental model of metabolic syndrome and menopause. Menopause, 19:562-568. doi: 10.1097/gme.0b013e3182358c9c.

Sanchez-Lozada, L.G., Lanaspa, M.A., Cristóbal-García, M., García-Arroyo, F., Soto, V., Cruz-Robles, D., et al. 2012. Uric acid-induced endothelial dysfunction is associated with mitochondrial alterations and decreased intracellular ATP concentrations. Nephron Exp. Nephrol. 121:e71-e78. doi: 10.1159/000345509. 
Sánchez-Lozada, L.G., Tapia, E., Jimenez, A., Bautista, P., Cristóbal, M., Nepomuceno, T., et al. 2007. Fructose-induced metabolic syndrome is associated with glomerular hypertension and renal microvascular damage in rats. Am. J. Physiol. Renal. Physiol. 292: F423-F429. doi:10.1152/ajprenal.00124.2006.

Sato, Y., Ito, T., Udaka, U., Kanisawa, M., Noguchi, Y., Cushman, S.W., and Satoh, S. 1996. Immunohistochemical localization of facilitated-diffusion glucose transporters in rat pancreatic islets. Tissue Cell. 28: 637-43. PMID: 9004533.

Sautin, Y.Y, Nakagawa, T., Zharikov, S., and Johnson, R.J. 2007. Adverse effects of the classic antioxidant uric acid in adipocytes: NADPH oxidase-mediated oxidative/nitrosative stress. Am. J. Physiol. Cell Physiol. 293: 584-96. doi:10.1152/ajpcell.00600.2006.

Schaan, B.D., Silva, A.M., and Irigoyen, M.C. 2010. Endothelial dysfunction in diabetes mellitus and insulin resistance states: role of oxidative stress and potential therapeutic opportunities. Arq. Bras. Endocrinol. Metabol. 54: 514-515. PMID:20857055.

Senador, D., Key, M., Brosnihan, K.B., Irigoyen, M.C., Elased, K.M., and Morris, M. 2010. Cardiovascular interactions between losartan and fructose in mice. J. Cardiovasc. Pharmacol. Ther. 15: 68-77. doi:10.1177/1074248409351409.

Shen, G.X. 2010. Oxidative stress and diabetic cardiovascular disorders: roles of mitochondria and NADPH oxidase. Can. J. Physiol. Pharmacol. 88: 241-248. doi: 10.1139/Y10-018.

Shinozaki, K., Nishio, Y., Okamura, T., Yoshida, Y., Maegawa, H., Kojima, H., et al. 2000. Oral administration of tetrahydrobiopterin prevents endothelial dysfunction and vascular oxidative stress in the aortas of insulin-resistant rats. Circ. Res. 87: 566-573. PMID:11009561

Sies, H. 1997. Oxidative stress: oxidants and antioxidants. Exp. Physiol. 82: 291-5. PMID:9129943 
Silva, R.J., Bernardes, N., Brito, J.O., Sanches, I.C., Irigoyen, M.C., and De Angelis, K. 2011. Simvastatin-Induced Cardiac Autonomic Control Improvement In Fructose-Fed Female Rats. Clinics, 66: 1793-1796. PMID:22012053.

Singal, P.K., Khaper, N., Palace, V., and Kumar, D. 1998. The role of oxidative stress in the genesis of heart disease. Cardiovasc. Res. 40: 426-432. PMID:10070480.

Singh, A.K., Amlal, H., Haas, P.J., Dringenberg, U., Fussell, S., Barone, S.L., et al. 2008. Fructose-Induced Hypertension: Essential Role Of Chloride And Fructose Absorbing Transporters PAT1 And Glut5. Kidney Int. 74: 438-447. doi:10.1038/ki.2008.184.

Sorensen, L.B., Raben, A., Stender, S., and Astrup, A. 2005. Effect of sucrose on inflammatory markers in overweight humans. Am. J. Clin. Nutr. 82: 421-7, 2005. PMID:16087988.

Srikanthan, K., Feyh, A., Visweshwar, H., Shapiro, J.I., and Sodhi, K. 2016. Systematic review of metabolic syndrome biomarkers: A panel for early detection, management, and risk stratification in the west virginian population. Int. J. Med. Sci. 13:25-38. doi:10.7150/ijms.13800.

Stanhope, K.L., Schwarz, J.M., Keim, N.L., Griffen, S.C., Bremer, A.A., Graham, J.L., et al. 2009. Consuming fructose-sweetened, not glucose sweetened, beverages increases visceral adiposity and lipids and decreases insulin sensitivity in overweight/obese humans. J. Clin. Invest. 119: 1322-1334. doi:10.1172/JCI37385.

Styskal, J., Van, Remmen, H., Richardson, A., and Salmon, A.B. 2012. Oxidative stress and diabetes: what can we learn about insulin resistance from antioxidant mutant mouse models? Free Radic. Biol. Med.; 52: 46-58. doi:10.1016/j.freeradbiomed.2011.10.441. 
Sun, H-L., Pei, D., Lue, K-H, and Chen, Y-L. 2015. Uric acid levels can predict metabolic syndrome and hypertension in adolescents: a 10-year longitudinal study. PLoS ONE 10: 1-10. doi: 10.1371/journal.pone.0143786.

Taniyama, Y., and Griendling, K.K. 2003. Reactive oxygen species in the vasculature: molecular and cellular mechanisms. Hypertension, 42:1075-81. doi:10.1161/01.HYP.0000100443.09293.4F.

Tappy, L., Le, K.A., Tran, C., and Paquot, N. 2010. Fructose and metabolic diseases: new findings, new questions. Nutrition, 26: 1044-1049. doi: 10.1016/j.nut.2010.02.014.

Te Morenga, L.A., Howatson, A.J., Jones, R.M., and Mann, J. 2014. Dietary sugars and cardiometabolic risk: systematic review and meta-analyses of randomized controlled trials of the effects on blood pressure and lipids. Am. J. Clin. Nutr. 100:65-79. doi: 10.3945/ajcn.113.081521.

Tedgui, A., and Mallat, Z. 2006. Cytokines in atherosclerosis: Pathogenic and regulatory pathways. Physiol. Rev. 86: 515-581. doi:10.1152/physrev.00024.2005.

Tentolouris N, Argyrakopoulou G., and Katsilambros, N. 2008. Perturbed Autonomic Nervous System Function In Metabolic Syndrome. Neuromolecular Med. 10:169-178. doi: 10.1007/s12017-008-8022-5.

Tentolouris, N., Liatis, S., and Katsilambros, N. 2006. Sympathetic system activity in obesity and metabolic syndrome. Ann. N. Y. Acad. Sci. 1083:129-152. doi:10.1196/annals.1367.010.

Tilg, H., and Hotamisligil, G.S. 2006. Nonalcoholic fatty liver disease: Cytokineadipokine interplay and regulation of insulin resistance. Gastroenterology, 131: 934-45. doi:10.1053/j.gastro.2006.05.054.

Tracey, K.J. 2002. The inflammatory reflex. Nature, 420: 853-859. doi:10.1038/nature01321. 
Trichopoulou A, Costacou T, Bamia C, Trichopoulos D. 2003. Adherence to a mediterranean diet and survival in a greek population. N. Engl. J. Med. 348: 2599-608. DOI: 10.1056/NEJMoa025039.

Tsochatzis, E., Papatheodoridis, G.V., and Archimandritis, A.J. 2006. The evolving role of leptin and adiponectin in chronic liver diseases. Am. J. Gastroenterol. 101: 2629-40. doi:10.1111/j.1572-0241.2006.00848.x.

Van Gaal, L.F., Mertens, I.L., and De Block, C.E. 2006. Mechanisms linking obesity with cardiovascular disease. Nature, 444: 875-880. doi:10.1038/nature05487.

Van Guilder, G.P., Hoetzer, G.L., Greiner, J.J., Stauffer, B.L., and Desouza, C.A. 2006. Influence of metabolic syndrome on biomarkers of oxidative stress and inflammation in obese adults. Obesity, 14: 2127-31. doi:10.1038/oby.2006.248.

Vasdev, S., Ford, C.A., Longerich, L., Gadag, V., and Wadhawan, S. 1998. Role of aldehydes in fructose induced hypertension. Mol. Cell. Biochem. 181: 1-9. PMID: 9562236.

Vasdev, S., Gill, V., and Singal, P.K. 2006. Modulation of oxidative stress-induced changes in hypertension and atherosclerosis by antioxidants. Exp. Clin. Cardiol. 11: 206-216. PMID:18651033

Vaziri, N.D. 2004. Roles of oxidative stress and antioxidant therapy in chronic renal disease and hypertension. Curr. Opin. Nephrol. Hypertens. 9:13-93. PMID:15090865

Vazquez-Prieto, M.A., Lanzi, C.R., Lembo, C., Galmarini, C.R., Miatello, R.M. 2011. Garlic and onion attenuates vascular inflammation and oxidative stress in fructose-fed rats. J. Nutr. Metabol. 2011:1-7. http://dx.doi.org/10.1155/2011/475216.

Vaz, M., Jennings, G., Turner, A., Cox, H., Lambert, G., and Esler, M. 1997. Regional sympathetic nervous activity and oxygen consumption in obese normotensive human subjects. Circulation, 96: 3423-3429. PMID:9396437. 
Verma, S., and Anderson, T.J. 2002. Fundamentals of endothelial function for the clinical cardiologist. Circulation, 105: 546-549. PMID:11827916.

Verma, S., Bhanot, S., and Mcneill, J.H. 1996. Decreased vascular reactivity in metformin-treated fructose-hypertensive rats. Metabolism, 45: 1053-5.

Verma, S., Bhanot, S., and McNeill, J.H. 1999. Sympathectomy prevents fructose induced hyperinsulinemia and hypertension. Eur. J. Pharmacol. 373: R1-R4. PMID:10414447.

Velázquez-López, L., Santiago-Díaz, G., Nava-Hernández, J., Muñoz-Torres, A.V., Medina-Bravo, P., and Torres-Tamayo, M. 2014. Mediterranean-style diet reduces metabolic syndrome components in obese children and adolescents with obesity. BMC Pediatrics, 14:175. doi:10.1186/1471-2431-14-175.

Videla, L.A., Rodrigo, R., Araya, J., and Poniachik, J. 2004. Oxidative stress and depletion of hepatic long-chain polyunsaturated fatty acids may contribute to nonalcoholic fatty liver disease. Free Radic. Biol. Med. 37: 1499-507. doi:10.1016/j.freeradbiomed.2004.06.033

Vidigal, F.C., Bressan, J., Babio, N., and Salas-Salvadó, J. 2013. Prevalence of metabolic syndrome in Brazilian adults: a systematic review. BMC Public Health, 13:1198. doi: 10.1186/1471-2458-13-1198.

Vincent, H.K., Bourguignon, C., and Vincent, K.R. 2006. Resistance training lowers exercise-induced oxidative stress and homocysteine levels in overweight and obese older adults. Obesity, 14: 1921-1930. doi:10.1038/oby.2006.224.

Vlassara, H., and Striker, G.E. 2011. AGE restriction in diabetes mellitus: a paradigm shift. Nat. Rev. Endocrinology, 7: 526-539. doi:10.1038/nrendo.2011.74.

Wagner, A., Dallongeville, J., Haas, B., Ruidavets, J.B., Amouyel, P., Ferrières, J., Simon, C., and Arveiler, D. 2012. Sedentary behavior, physical activity and dietary 
patterns are independently associated with the metabolic syndrome. Diabetes Metab. 38: 428-435. doi:10.1016/j.diabet.2012.04.005.

Weisberg, S.P., McCann, D., Desai, M., Rosenbaum, M., Leibel, R.L., and Ferrante, A.W.Jr. 2003. Obesity is associated with macrophage accumulation in adipose tissue. J. Clin. Invest. 112: 1796-1808. doi:10.1172/JCI19246.

WHO. 2003. Joint WHO/FAO Expert Consultation. Diet, Nutrition and the Prevention of Chronic Diseases. WHO Technical Report Series. 916.

Wichi, R.B., De Angelis, K., Jones, L., and Irigoyen, M.C. 2009. A brief review of chronic exercise intervention to prevent autonomic nervous system changes during the aging process. Clinics, 64: 253-258. doi: 10.1590/S1807-59322009000300017.

Yi, C.X., Al-Massadi, O., Donelan, E., Lehti, M., Weber, J., Ress, C., Trivedi, C., Müller, T.D., Woods, S.C., and Hofmann, S.M. 2012. Exercise protects against high-fat diet-induced hypothalamic inflammation. Physiol. Behav. 106: 485-90. doi:10.1016/j.physbeh.2012.03.021.

Yuan, Y., Jiao, X., Lau, W.B., Wang, Y., Christopher, T.A., Lopez, B.I, et al. 2010. Thioredoxin glycation: A novel posttranslational modification that inhibits its antioxidant and organ protective actions. Free Radic. Biol. Med. 49: 332-338. doi:10.1016/j.freeradbiomed.2010.04.017.

Zhao, C.X., Xu, X., Cui, Y., Wang, P., Wei, X., Yang, S., et al. 2009. Increased endothelial nitric-oxide synthase expression reduces hypertension and hyperinsulinemia in fructose-treated rats. J. Pharmacol. Exp. Ther. 328: 610-620. doi:10.1124/jpet.108.143396. 


\section{$\underline{\text { Figure legends }}$}

Figure 1: Fructose induced oxidative stress in metabolic syndrome. Excessive consumption of fructose leads to enhanced production of uric acid, increased lipogenesis and triglycerides. Elevated lipid levels and uric acid induce oxidative stress by depressing the activities of endogenous antioxidant enzymes and reduced glutathione (GSH) and increasing the activities of prooxidant enzymes like NADPH oxidase (NOX), xanthine oxidase (XO) and uncoupled nitric oxide synthase (NOS) along with over production of reactive oxygen species (ROS) and reactive nitrogen species (RNS). These reactive species aggravate lipid and protein oxidation, DNA damage, cell organelle dysfunction and cell death, finally leading to cardiometabolic dysfunctions viz., hypertension, insulin resistance, LDL oxidation, atherosclerosis, inflammation, endothelial dysfunction etc.

Figure 2: Fructose mediated inflammatory response in metabolic syndrome. Hyperlipidemia induced by fructose leads to mitochondrial dysfunction and overproduction of ROS. This in turn leads to monocyte/macrophage infiltration in different tissues along with the activation of various inflammatory cascades which include the release of inflammatory markers such as TNF- $\alpha$, MCP-1, IL-6, IL-1 $\beta$ etc. and inhibition of anti-inflammatory cytokine IL-10, along with adiponectin and POX-1. This inflammatory response leads to further complications of metabolic syndrome and tissue damage. 
Table 1: Prevalence of Metabolic syndrome

\begin{tabular}{|c|c|c|}
\hline Country/Region & Prevalence (\%) & Source \\
\hline United States of America & 22.9 & $\begin{array}{c}\text { Beltran-Sanchez et al., } \\
2013\end{array}$ \\
\hline Latin American countries & $14-27$ & Escobedo et al. 2009 \\
\hline Brazil & $28.9-29.6$ (Adults) & Vidigal et al. 2013 \\
\hline Portugal & 27.6 & Fonseca et al. 2012 \\
\hline Spain & 26.6 & $\begin{array}{c}\text { Corbaton-Anchuelo et } \\
\text { al. 2013 }\end{array}$ \\
\hline France & 25 (Males) & Wagner et al. 2012 \\
\hline Italy & 15.3 (Females) & Lacoviello et al. 2007 \\
\hline & 28 (Males) & \\
\hline
\end{tabular}




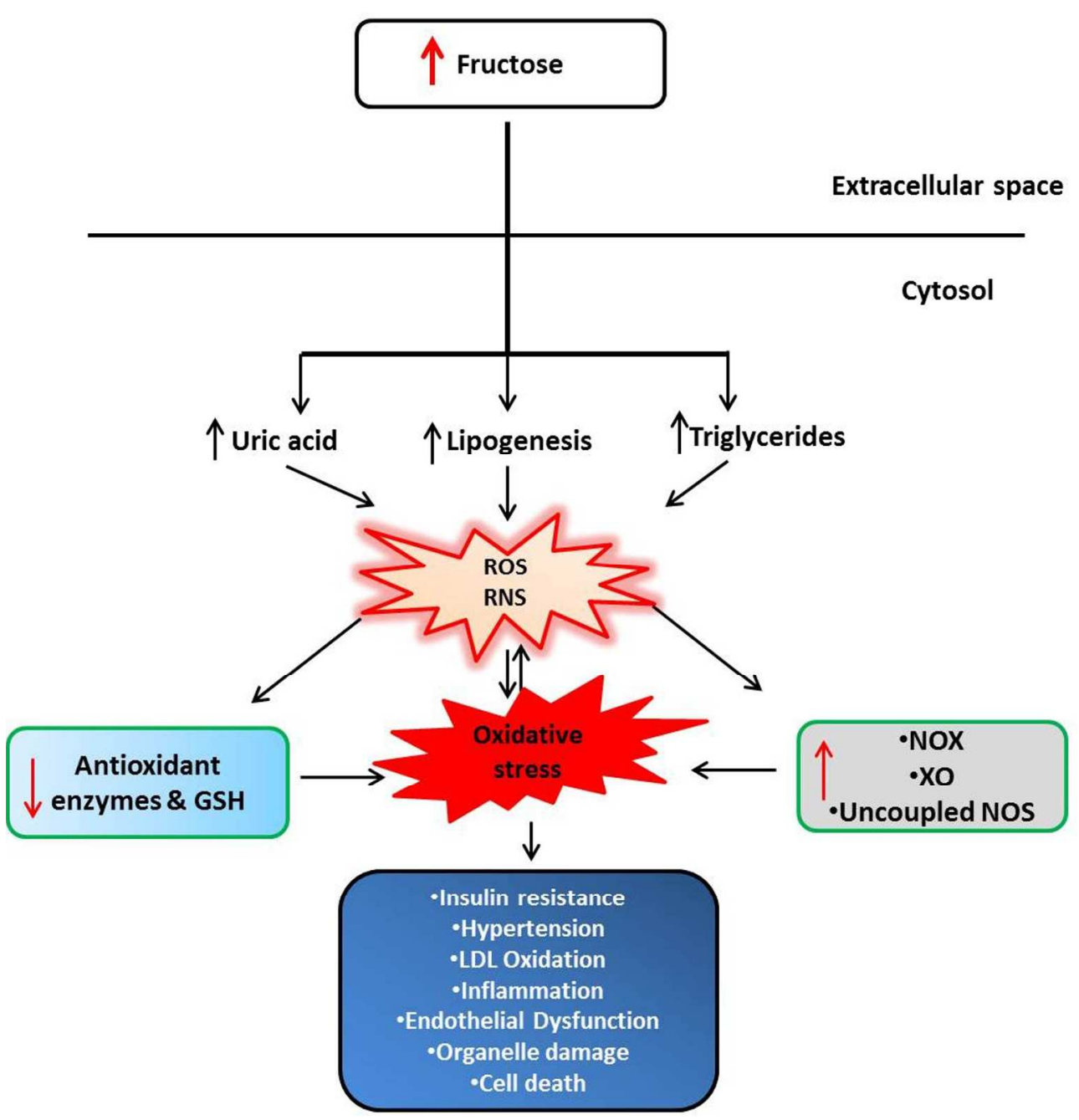

Figure 1: Fructose induced oxidative stress in metabolic syndrome.

$183 \times 186 \mathrm{~mm}(300 \times 300 \mathrm{DPI})$ 


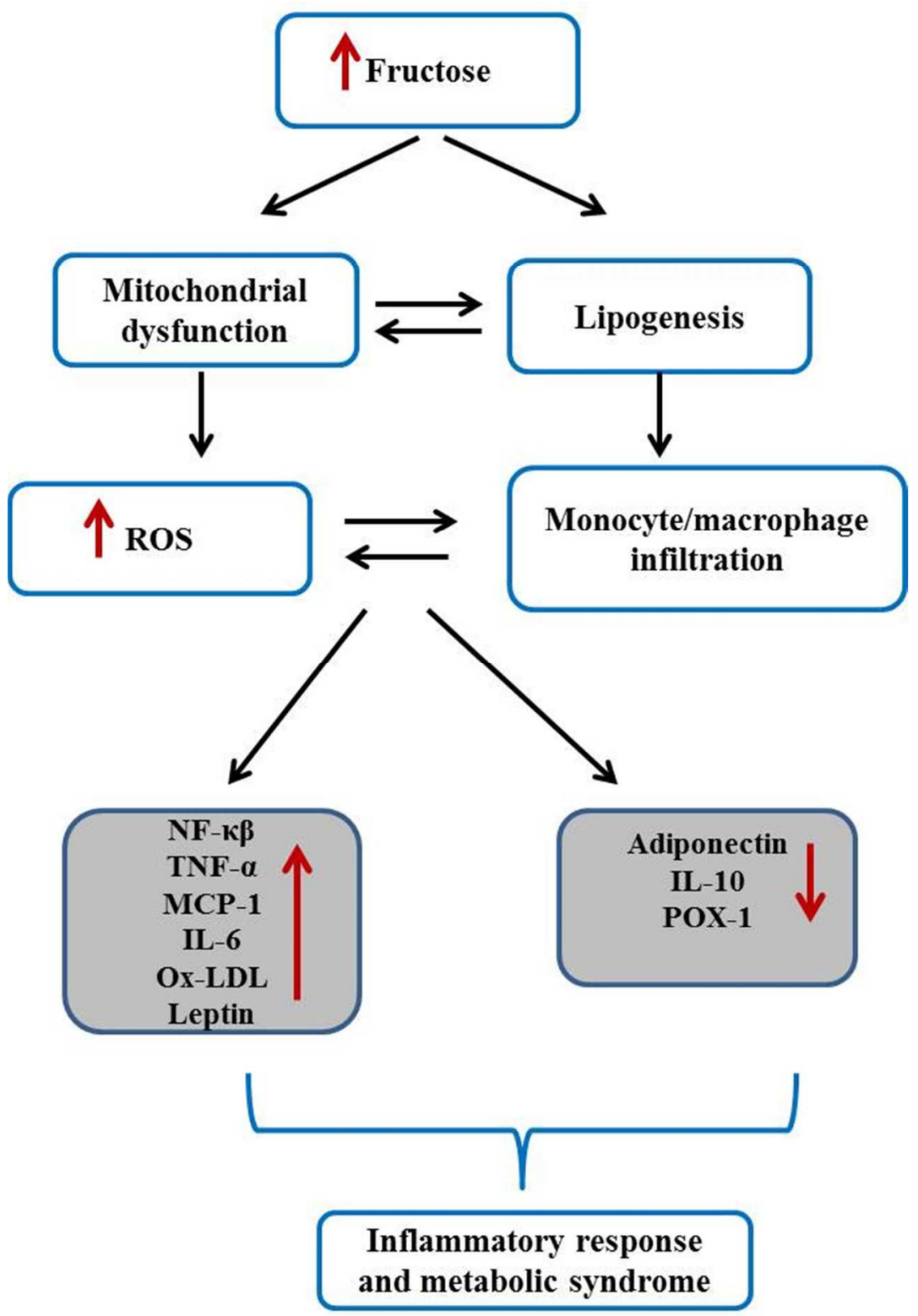

Figure 2: Fructose mediated inflammatory response in metabolic syndrome. $202 \times 296 \mathrm{~mm}(300 \times 300$ DPI $)$ 